\title{
A Review on the Processing Technologies for Corrosion Resistant Thermoelectric Oxide Coatings
}

Yong X. Gan

Citation: Gan, Y.X. A Review on the Processing Technologies for Corrosion Resistant Thermoelectric Oxide Coatings. Coatings 2021, 11, 284. https://doi.org/10.3390/ coatings11030284

Academic Editor: Véronique Vitry

Received: 19 January 2021

Accepted: 24 February 2021

Published: 28 February 2021

Publisher's Note: MDPI stays neutral with regard to jurisdictional claims in published maps and institutional affiliations.

Copyright: (C) 2021 by the author. Licensee MDPI, Basel, Switzerland. This article is an open access article distributed under the terms and conditions of the Creative Commons Attribution (CC BY) license (https:// creativecommons.org/licenses/by/ $4.0 /)$.
Department of Mechanical Engineering, College of Engineering, California State Polytechnic University Pomona, 3801 W Temple Avenue, Pomona, CA 91768, USA; yxgan@cpp.edu; Tel.: +1-909-869-2388

\begin{abstract}
Oxide coatings are corrosion resistant at elevated temperatures. They also show intensive phonon scattering and strong quantum confinement behavior. Such features allow them to be used as new materials for thermoelectric energy conversion and temperature measurement in harsh environments. This paper provides an overview on processing thermoelectric oxide coatings via various technologies. The first part deals with the thermoelectricity of materials. A comparison on the thermoelectric behavior between oxides and other materials will be made to show the advantages of oxide materials. In the second part of the paper, various processing technologies for thermoelectric metal oxide coatings in forms of thin film, superlattice, and nanograin powder will be presented. Vapor deposition, liquid phase deposition, nanocasting, solid state approach, and energy beam techniques will be described. The structure and thermoelectric property of the processed metal oxide coatings will be discussed. In addition, the device concept and applications of oxide coatings for thermoelectric energy conversion and temperature sensing will be mentioned. Perspectives for future research will be provided as well.
\end{abstract}

Keywords: metal oxide coating; thermoelectricity; processing; manufacturing technology; vapor deposition; liquid phase deposition; nanocasting; solid state processing; energy beam technique; superlattice

\section{Introduction}

Thermoelectric materials can generate electricity when a temperature difference exists. Such a function allows a thermoelectric module to be used as an energy converter [1] or thermal sensor [2]. For the energy conversion application, the module can be used either as an electrical power generator [3] or as a cooler [4]. The thermoelectric property of a material may be evaluated by a characteristic parameter called the thermoelectric figure of merit $z$, which can be expressed as the following equation [5]:

$$
z=\frac{\sigma S^{2}}{\kappa}
$$

where $S$ is the Seebeck coefficient, $\mathrm{k}$ is the thermal conductivity, and $\sigma$ is the electrical conductivity. Based on the definition of $z$, the thermoelectric energy conversion performance of a material can be quantified by a dimensionless figure of merit $z T$ : The calculation of $z T$ is shown as follows:

$$
z T=\frac{\sigma S^{2}}{\kappa} T
$$

where $T$ is the absolute temperature. It is estimated that a $z T$ value of 1.0 corresponds to an energy conversion efficiency around $10 \%$.

Many researchers have studied materials processing and module manufacturing technologies with the aim of identifying high efficiency thermoelectric energy conversion materials and systems. Metallic alloys and intermetallic compounds are the most commonly researched thermoelectric (TE) materials. Among various metallic TE materials, 
skutterudites (named after the city of Skotterud, Norway), a cobalt arsenide mineral containing variable amounts of nickel and iron substituting for cobalt with a general formula of $\mathrm{CoAs}_{3}$, shows considerably strong thermoelectric effect in the temperature range from 400 to $600{ }^{\circ} \mathrm{C}$ with the $z T$ values as high as 0.85 at $400{ }^{\circ} \mathrm{C}$ and as high as 1.9 at $550{ }^{\circ} \mathrm{C}$ for doped skutterudites [6]. Another group of TE metallic materials consists of the HalfHeusler $(\mathrm{HH})$ alloys. Heusler alloys are named after the German mining engineer and chemist Friedrich Heusler who investigated $\mathrm{Cu}-\mathrm{Mn}-\mathrm{Al}$ alloys in 1900s. They are magnetic intermetallic compounds with the face-centered cubic (FCC) crystal structure. Some of these alloys are ferromagnetic even though their constituent atoms are non-ferromagnetic as elements. There are three families of Heusler alloys, i.e., full Heuslers with the general formula of "A2BC", Half-Heuslers $(\mathrm{HH})$ with the chemical composition of "ABC", and inverse Heuslers with the "ABAC" formula. Half-Heusler $(\mathrm{HH})$ compounds based on XNiSn and $\mathrm{XCoSb}(\mathrm{X}=\mathrm{Ti}, \mathrm{Zr}$, or $\mathrm{Hf})$ have increasing importance as thermoelectric materials for converting waste heat into electricity [7-9]. This is because the figure of merit, $z T$, for some Half-Heusler $(\mathrm{HH})$ alloys, for example, $\mathrm{Ti}_{0.5} \mathrm{Zr}_{0.5} \mathrm{NiSn}$ and $\mathrm{Ti}_{0.15} \mathrm{Nb}_{0.85} \mathrm{FeSb}$ is as high as 0.8 and the thermoelectric conversion efficiency, $\eta$, is enhanced close to $10 \%$ [10-12].

Chalcogenides are covalently bonded compounds containing one or more chalcogen elements (S, Se, Te, or Po) as a substantial constituent. A recent review on chalcogenides as thermoelectric materials was published [13]. It is reported that the outstanding thermoelectric performance of chalcogenides depends strongly on the decrease in thermal conductivity. The thermal conductivity reduction in some chalcogenides, for example, $\mathrm{PbTe}$ [14], is due to the existing heavy elements. However, it has been found that in some other cases (e.g., $\mathrm{Tl}_{(10-x)} \mathrm{Sn}_{x} \mathrm{Te}_{6}$ and $\mathrm{Tl}_{(10-x)} \mathrm{Pb}_{x} \mathrm{Te}_{6}$ [15]) heavy elements are not the major contributors to the low thermal conductivity. Instead, the stereo chemically active lone pair is the main reason for low thermal conductivity as found in the SnSe compound [16,17]. The high ion mobility also contributes to the low thermal conductivity. $\mathrm{Cu}$ or $\mathrm{Ag}$ cations exhibit good ion mobility in thermoelectric materials such as $\mathrm{Cu}_{2} \mathrm{Se}$ [18], $\mathrm{Ba}_{3} \mathrm{Cu}_{(14-\delta)} \mathrm{Te}_{12}$ [19], and $\mathrm{Tl}_{2} \mathrm{Ag}_{12} \mathrm{Se}_{7}[20]$.

In general, a good thermoelectric material is an "electron crystal and phonon glass" which has high electrical conductivity and low thermal conductivity at the same time. Among various materials, semiconducting silicon and its related compounds (both metallic and nonmetallic silicates) show such unique behavior, which means that the thermal conductivity and electrical conductivity are decoupled. Doped-silicon has good conductivity, comparable to that of a metal, but keeps very low thermal conductivity, like that of a ceramic material [21]. Zhou and $\mathrm{Hu}$ [22] predicted the further reduction of the thermal conductivity of polycrystalline Si nanowires by introducing disorders to cause more effective phonon scattering. Metal silicates and their nanocomposites have been reported to possess high thermoelectric figure of merit $(z T)$ values because of their low thermal conductivity and high Seebeck coefficient values [23-29].

Compared to the aforementioned thermoelectric materials, most of the metal oxides exhibit modest thermoelectric properties due to their relatively low electrical conductivity and high thermal conductivity. However, metal oxides have good high temperature stability in air. They are almost inert in various corrosion media. In addition, they are easy to process and inexpensive. Such advantages provide the motivation to search for good thermoelectric material-based oxides. Several groups of oxide materials including binary oxides, perovskite oxides, and oxidized bismuth selenide have demonstrated promising thermoelectric performance as described in [30]. It is revealed that some of the layered oxides have certain advantages in view of their peculiar transport behavior [31]. A review of various layered oxides for thermoelectric applications is presented in [32]. Numerical studies on the structural stability and thermoelectric property of the Ca-Mn based oxide were reported [33].

Metal oxides have been extensively used to build multiple functional devices, for example, photovoltaic/thermoelectric duel functionality modules based on the photoSeebeck effect [34-36]. As reported by Shiraishi et al. [37], the photo-Seebeck effect in 
the perovskite titanium oxide, $\mathrm{SrTiO}_{3}$, leads to the high mobility of the photon-induced electrons by the $405 \mathrm{~nm}$ laser excitation, which is considered as an additional contribution to the increased electrical conductivity. In addition, the absolute value of the Seebeck coefficient was found very high, i.e., in the range from 0.25 to $2.2 \mathrm{mV} / \mathrm{K}$ under the $450 \mathrm{~nm}$ laser illumination. In some other oxide based thermoelectric materials with different compositions and structures [38-43], how the photon-induced carriers contribute to the thermoelectric behavior, i.e., the photo-Seebeck effect was examined as well. For example, the wide-gap oxide semiconductor $\mathrm{ZnO}$ shows the strong photo-Seebeck effect [38-40]. Okazaki et al. [38] investigated $\mathrm{ZnO}$ by measuring its electrical conductivity and Seebeck coefficient under light illumination. Both Seebeck coefficient and conductivity of the oxide were found sensitive to the photon energy of the illumination light sources. A parallelcircuit model was used to evaluate the contributions from the photo-induced carriers to the conductivity and the Seebeck coefficient. It was found that the results obtained from their studies are similar to those from doped semiconductors. That is, the light illumination increases both the carrier concentration and the mobility, as also found in doped $\mathrm{ZnO}$ with impurities.

Another important wide-band gap oxide, $\mathrm{WO}_{3}$, also demonstrates the photo-Seebeck effect [41,42]. Suzuki et al. [41] measured the thermoelectric power of a platinum-loaded tungsten trioxide $\left(\mathrm{Pt} / \mathrm{WO}_{3}\right)$ thin film exposed to an ultraviolet (UV) light source. The UV light-induced band-gap excitation was observed. It has been found that the electrical conductivity $(\sigma)$ is increased, whereas the absolute value of the Seebeck coefficient $(S)$ is decreased due to the photochromic reactions in $\mathrm{WO}_{3}$. The opposite behavior, a decrease in $\sigma$ and an increase in $S$, was observed in the presence of $\mathrm{O}_{2}$ after dark storage. Photo-Seebeck effect was also detected in response to the visible-light irradiation of a $\mathrm{Pt} / \mathrm{WO}_{3}$ specimen in the absence of $\mathrm{O}_{2}$ after chromic reactions. Under visible-light irradiation, both $\sigma$ and the absolute value of $S$ were increased.

Mondal et al. [43] observed the photo-Seebeck effect in tetragonal PbO single crystals. The photo-induced carrier concentration was modeled. Transport data were obtained by measurement. It is confirmed that photo-induced carriers contribute to the change in the transport behavior. The electrical conductivity increases by more than two orders in magnitude, but the Seebeck coefficient decreases from 1.9 to $0.8 \mathrm{mV} / \mathrm{K}$ with the increase of the photon flux density. The power factor $\left(\sigma S^{2}\right)$ increases under illumination. The photo-induced carrier concentration increases almost linearly with the increase of photon flux density. The power factor was found increasing due to the synergistic photo-doping effect on the thermoelectric property of $\mathrm{PbO}$. The career mobility decreases by illumination, and the reduction rate strongly relies on the photon energy of the illumination source.

In view of metal oxide processing and manufacturing technologies, the powder metallurgical method [44-47] is especially suitable for making bulk oxides. For metallic oxide coatings, liquid phase processing [48,49], vapor phase deposition [50], energy beam technique [51], and high temperature or molten metal electrochemical oxidation [52] have been widely used. There are some other techniques developed for metal oxide coating preparation. For example, solution-gelation approach [53], electrodeposition or electroplating [54], electrospinning [55], liquid phase deposition [56], templated assisted nanocasting [57], pulsed laser deposition [58], and low temperature electrochemical processing [59] have been utilized.

This paper deals with the advances in the thermoelectric oxide coatings with the emphasis on processing technologies. The rest of the paper is organized as follows. A review on the processing and manufacturing techniques for thermoelectric metal oxide nanomaterials will be introduced first. Thermoelectric oxide coatings consisting of thin films, nanopowders, superlattices, and low dimensional heterogeneous oxides [60] will be presented. Device fabrication and characterization of the thermoelectric properties of oxide coatings will be briefly introduced following the discussion on processing and manufacturing technologies in each subsection. Perspectives to future research directions will be discussed and concluding remarks will be drawn. 


\section{Thermoelectric Oxide Coating Processing Technologies}

There are many methods for oxide coating preparation and manufacturing. In this part, the commonly used vapor deposition including physical and chemical vapor deposition, solid state approach, liquid phase deposition, nanocasting, and energy beam techniques including laser beam deposition, ion beam sputtering, and electron beam evaporation will be introduced.

\subsection{Vapor Phase Deposition}

Vapor-phase deposition consists of physical vapor deposition (PVD), chemical vapor deposition (CVD), plasma enhanced deposition (PED), magnetic field enhanced deposition (MFED) etc. There are two major types of physical vapor deposition (PVD), thermal evaporation and sputtering. Both thermal evaporation and sputtering can deliver uniform coatings. Chemical vapor deposition (CVD) consists of ambient pressure CVD, low pressure CVD, metal organic compound CVD (MOCVD), etc. The plasma technique can be integrated into both PVD and CVD to achieve the so-called plasma-enhanced deposition. The plasma effect can change the deposition rate significantly. Magnetic field enhanced deposition (MFED) is suitable for increasing the deposition rate of oxide materials that are sensitive to an externally added magnetic field. The deposition of transition metal oxide coatings such as $\mathrm{NiO}, \mathrm{CoO}$, and $\mathrm{Fe}_{2} \mathrm{O}_{3}$ can benefit from an added magnetic field because the deposition rate could be increased more than 500 times. Vapor-phase deposition, as described in the review article [50], has been extensively studied for preparation of oxide coatings. It is considered as one of the least expensive ways for large scale production due to the use of simple, cost-effective equipment. This technique is suitable for synthesizing various oxide coatings consisting of either wide-band or narrow-band oxide compounds. Typical examples of oxide coatings processed by vapor phase deposition include but are not limited to titanium dioxide $\left(\mathrm{TiO}_{2}\right)$ [61], zinc oxide $(\mathrm{ZnO})$ [62], alumina $\left(\mathrm{Al}_{2} \mathrm{O}_{3}\right)$ [63], tin dioxide $\left(\mathrm{SnO}_{2}\right)$ [64], copper oxide $(\mathrm{CuO})$ [65], gallium oxide $\left(\beta-\mathrm{Ga}_{2} \mathrm{O}_{3}\right)$ [66], and hematite $\left(\alpha-\mathrm{Fe}_{2} \mathrm{O}_{3}\right)$ [67]. Some other oxides such as indium oxide $\left(\mathrm{In}_{2} \mathrm{O}_{3}\right)$ [68], cadmium oxide ( $\mathrm{CdO})$ [69], and ceria $\left(\mathrm{CeO}_{2}\right)$ [70] can also be processed by this technique.

In the work performed by Ahmoum et al. [71], nickel-doped zinc oxide was made by thermal co-evaporating of $\mathrm{Ni}$ and $\mathrm{Zn}$ in $\mathrm{O}_{2}$ flow under different temperature conditions. Alumina was used as the substrate and kept at $300{ }^{\circ} \mathrm{C}$ during the co-evaporation deposition. The temperature of $\mathrm{Zn}$ source was maintained at $350{ }^{\circ} \mathrm{C}$. The Ni source (particles with a diameter around 1-3 $\mathrm{mm}$ ) was heated up to different temperatures of 1230,1250, and $1270{ }^{\circ} \mathrm{C}$. The initial pressure of the chamber was $8.5 \times 10^{-5} \mathrm{~Pa}$, and the working pressure during the deposition was kept at $1.2 \times 10^{-4} \mathrm{~Pa}$. The radio-frequency power was set at $380 \mathrm{~W}$ and the rate of $\mathrm{O}_{2}$ flow was $1.8 \mathrm{SCCM}$ to produce reactive oxygen atoms. The thicknesses of the Ni-doped $\mathrm{ZnO}$ film reached $740 \mathrm{~nm}$ after 350 min deposition. The electrical conductivity was measured in the temperature range from 50 to $300{ }^{\circ} \mathrm{C}$. The result can be found in Figure 1a [71]. With the test temperature increasing, the electrical conductivity showed a general increasing trend. The specimen deposited at the Ni source temperature of $1250{ }^{\circ} \mathrm{C}$ showed the highest conductivity. This specimen also showed the most increase of the electrical conductivity when the test temperature was raised. Its conductivity increased from 1800 to $3200(\mathrm{~S} / \mathrm{m})$. The Seebeck coefficient data were presented in Figure $1 \mathrm{~b}$ for the Ni-doped $\mathrm{ZnO}$ [71]. The specimens deposited at different Nisource temperatures are n-type. The higher the Ni-source temperature during deposition, the stronger the Seebeck effect. The absolute value of the Seebeck coefficient increases slightly with the increasing in the testing temperature. 


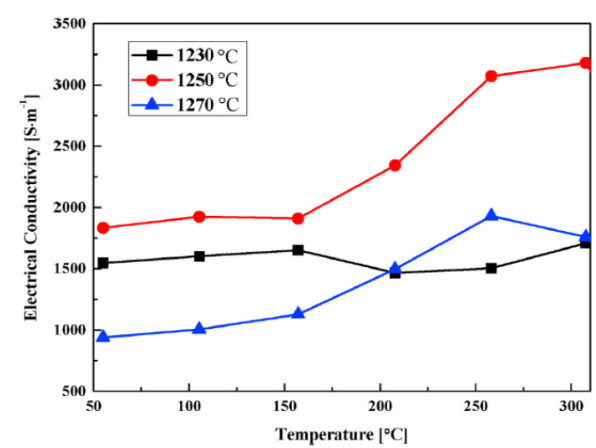

(a)

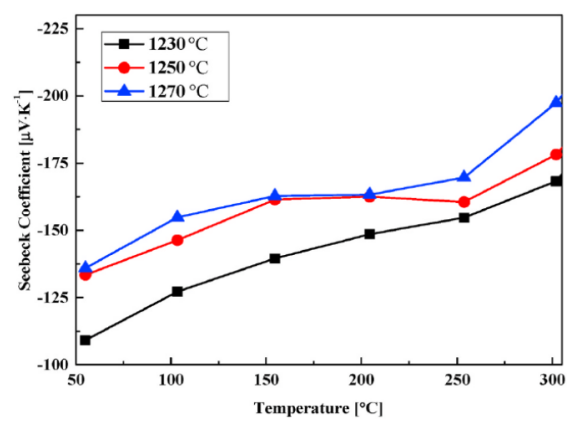

(b)

Figure 1. The electrical and thermoelectric properties of the Ni-doped ZnO made by thermal coevaporation: (a) electrical conductivity, and (b) Seebeck coefficient. Reprinted with permission from [71], @2020 Elsevier Ltd.

Many deposition techniques used for device fabrication allow the formation of multilayer coatings. They can be grouped into two large groups: Physical Vapor Deposition (PVD) and Chemical Vapor Deposition (CVD). CVD generally consists of introducing gaseous reagents into a reactor or deposition chamber. The reagents cause chemical reactions to occur on the surface of the material to be coated. This process leads to the growth of a coating on the surface of a substrate. Physical Vapor Deposition (PVD) includes a group of deposition techniques, which are common on the aspect that they allow the mass transport from a target material or a source material to the substrate to be coated. The process takes place in a compact chamber. Although thermal evaporation and plasma sputtering are the frequently used PVD techniques, integrating two or several processes together has caught more and more intention because of the advantage of the enhanced deposition rate. Typical integrated methods include magnetron plasma sputtering and plasma sputtering coupled with thermal evaporation. Figure 2 schematically shows the setups for these two integrated PVD techniques with more details available in [72].

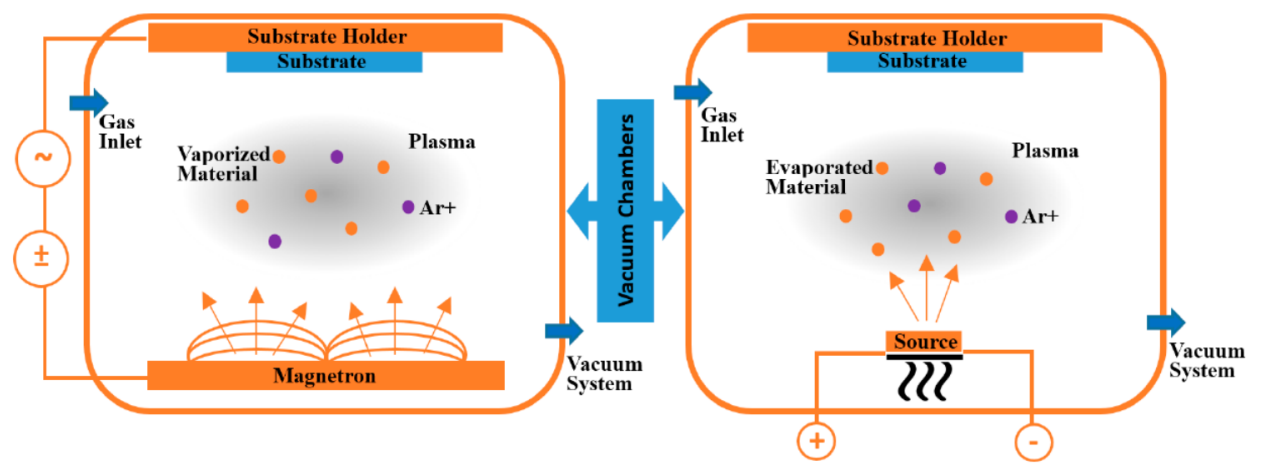

(a)

(b)

Figure 2. Schematic showing integrated physical vapor deposition (PVD) processes: (a) magnetron plasma sputtering, and (b) plasma enhanced thermal evaporation. Reproduced from [72], (C2018, the authors.

As compared to PVD, CVD is a much faster process for oxide coating deposition. It is considered as one of the most useful micro- and nanoscale fabrication techniques [4]. During CVD process, heterogeneous reactions may take place not only on a substrate but also in the gaseous phase. Therefore, the deposition rate is high, but the uniformity of the coatings may be low. A typical chemical vapor deposition process includes several stages. In the first stage, reactants and inert dilute gases flow into the chamber. In the second stage, gaseous species move towards the substrate and reactants adsorb onto the substrate. Then, adsorbed atoms migrate and participate into chemical reactions. The gaseous by-products of the reactions are desorbed from the surface of the specimens and removed from the 
reaction chamber. Finally, the exhaust is trapped by a recycling tank connected with a vacuum pump. To control the temperature precisely at different locations in the chamber, multi-zone resistant heaters may be used.

The deposition kinetics in a CVD process highly relies on the temperature condition. In the high-temperature range, the mass transfer controls the rate of deposition. In the low-temperature range, the chemical reaction determines the deposition rate. Transition between the two mechanisms in the intermediate temperature range can be found. Thus, the CVD kinetics can be divided into three regimes [3]. They are the mass transfer-limited regime, the reaction rate-limited regime, and the regime of transition between the previous two, which can be revealed by the relationship of logarithm deposition rate vs. the reciprocal of the reaction temperature. It is found that in the mass transfer limited regime, if CVD reactants arrive at the surface of specimens uniformly, the rate of deposition is not so sensitive to the temperature change. However, in the reaction rate limited region, the rate of deposition is highly sensitive to the temperature. It is very important to keep a uniform temperature distribution in the reaction zone to ensure the uniform deposition. Understanding such kinetics will help control the dimension, morphology, and structure of metal oxide coating products fabricated via CVD.

In the vapor deposition category, the chemical spray pyrolysis technique may be considered as one of the derived forms from chemical vapor deposition [73-76]. Another derived method is the reactive sputtering [77]. Such deposition methods are scalable and cost-effective. A precursor solution containing a metal organic compound or a metal salt dissolved into a solvent is chosen for the spraying or sputtering deposition. The substrate may be heated up at high temperatures, which allows organometallic compounds or inorganic metal salts to decompose in controlled atmospheres for oxide formation. Although these techniques are mainly developed for the deposition of oxide films, the spray pyrolysis deposition (SPD) has been successfully used for preparing titanium dioxide $\left(\mathrm{TiO}_{2}\right)$ nanofibers [78]. Under the careful controlled spraying rate, titanium dioxide nanofibers with a diameter of $30 \mathrm{~nm}$ in the coating were obtained on a hot glass substrate at $350{ }^{\circ} \mathrm{C}$ [78] The morphology of the deposited coating was analyzed. Two scanning electron microscopic images are shown in Figure 3. Both the top surface (left hand side image in Figure 3) and cross section (right hand side image in Figure 3) of the coating revealed the fibrous structure. From the inset (a) in the left-hand side image of Figure 3, it can be seen that the transverse size of the fiber is around $30 \mathrm{~nm}[78]$.
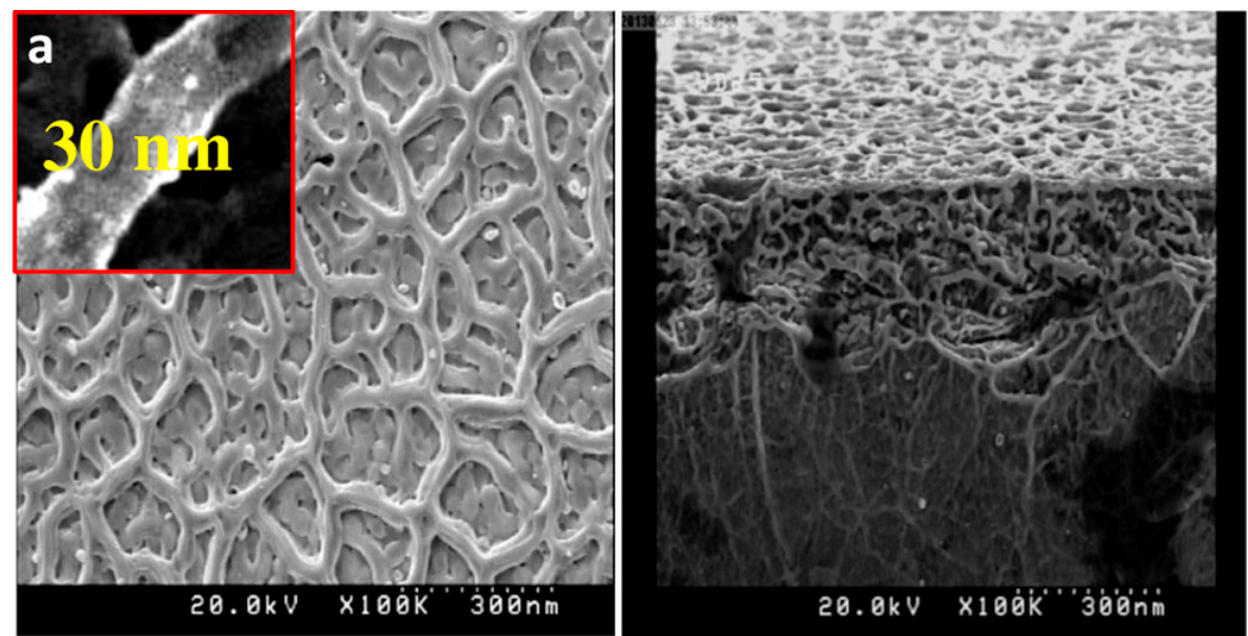

Figure 3. Scanning electron microscopic (SEM) images of the spray pyrolysis deposited (SPD) $\mathrm{TiO}_{2}$ coating containing nanofibers. Inset (a) shows the fiber size is around $30 \mathrm{~nm}$. The substrate temperature was $350{ }^{\circ} \mathrm{C}$. Reprinted with permission from [78], (c) 2015, Elsevier GmbH. 
The precursor used for titanium dioxide coating synthesis was a $0.1 \mathrm{M} \mathrm{TiCl} 3$ ethanol alcohol solution. A small amount of distilled water was added into the solution to initiate and sustain the following hydrolysis reaction of the titanium chloride.

$$
2 \mathrm{TiCl}_{3}+\mathrm{H}_{2} \mathrm{O} \rightarrow \mathrm{Ti}(\mathrm{OH})_{2} \mathrm{Cl}_{2}+\mathrm{TiCl}_{4}
$$

One of the products from the hydrolysis reaction, $\mathrm{Ti}(\mathrm{OH})_{2} \mathrm{Cl}_{2}$, decomposes into titanium dioxide $\left(\mathrm{TiO}_{2}\right)$ following the reaction formula below, as also presented in [78].

$$
\mathrm{Ti}(\mathrm{OH})_{2} \mathrm{Cl}_{2} \rightarrow \mathrm{TiO}_{2}+2 \mathrm{HCl} \uparrow
$$

It is also shown that titanium dioxide coating containing nano-pyramids can be made by the ultrasonic spray pyrolysis deposition on a glass substrate at an even higher temperature of $460{ }^{\circ} \mathrm{C}$ [79]. Pulsed solution feeding was used to spray a precursor solution containing titanium (IV) isopropoxide (TTIP) as the titanium source, acetylacetone (AcAc) as the stabilizer and ethanol as the solvent [80]. The concentration of TTIP in the ethanol solution was $6 \%$ in volume, and the molar ratio of TTIP to AcAc was kept as 1 to 2 . The solution was vaporized by a pneumatic spray system using compressed air as the carrier gas. $\mathrm{TiO}_{2}$ coatings on silicon substrate were obtained by the spray pyrolysis deposition at different substrate temperatures. The thickness of the coatings was controlled by the number of spray pulses. X-ray diffraction (XRD) experiments confirmed that the asdeposited $\mathrm{TiO}_{2}$ coatings grown at temperatures below $500{ }^{\circ} \mathrm{C}$ were amorphous. At the deposition or annealing temperature of $500{ }^{\circ} \mathrm{C}$ or above this temperature, the $\mathrm{TiO}_{2}$ coatings showed the crystalline anatase phase structure and were free of contaminants. Annealing at a higher temperature of $700{ }^{\circ} \mathrm{C}$ in air resulted in crystalline anatase structure formation for those films deposited even below $400{ }^{\circ} \mathrm{C}$. Films prepared at $435^{\circ} \mathrm{C}$ and annealed at $500{ }^{\circ} \mathrm{C}$ may show a hybrid structure of both rutile and anatase. More information of the spray pyrolysis deposition may be found in [81]. It is noted that the spray pyrolysis deposition typically includes a sol-gel process before the pyrolysis [82-85]. The sol-gel process allows the hydrolysis of metallic compounds to form the titanium dioxide coatings in the subsequent pyrolysis stage.

\subsection{Liquid Phase Deposition}

Liquid phase deposition (LPD) [3,4,86-91] is a one-step, low-cost method for metal oxide coating preparation. Typically, the hydrolysis or decomposition of a metalorganic compound or metal complex leads to the metal oxide coating deposition on a substrate. For the one-step deposition of $\mathrm{TiO}_{2}$ film, a mixed solution consisting of ammonium hexafluorotitanate $\left(\mathrm{NH}_{4}\right)_{2} \mathrm{TiF}_{6}(\mathrm{AHFT})$ and boric acid (BA) was used [91]. The hydrolysis reaction as shown below leads to the oxide film deposition on a substrate such as alumina.

$$
\left[\mathrm{TiF}_{6}\right]^{2-}+2 \mathrm{H}_{2} \mathrm{O} \leftrightarrow \mathrm{TiO}_{2}+6 \mathrm{~F}^{-}+4 \mathrm{H}^{+}
$$

To shift the hydrolysis to the right side of the equation, the $\mathrm{F}^{-}$ions should be consumed, which is achieved by the reaction generated by the added boric acid via Equation (6):

$$
\mathrm{H}_{3} \mathrm{BO}_{3}+4 \mathrm{H}^{+}+4 \mathrm{~F}^{-}=\left[\mathrm{BF}_{4}\right]^{-}+\mathrm{H}_{3} \mathrm{O}^{+}+2 \mathrm{H}_{2} \mathrm{O}
$$

Gao et al. [90] used LPD to make strontium titanium oxide: $\mathrm{SrTiO}_{3}$ (STO) thin films from an aqueous solution containing a metal-fluoro complex. The metal-fluoro complex was slowly hydrolyzed by adding water and boric acid $\left(\mathrm{H}_{3} \mathrm{BO}_{3}\right)$. Boric acid (BA) served as a fluorine scavenger destabilizing the fluoro-complex, and it promoted the precipitation of the oxide. The metal-fluoro complex was made using the $98.5 \%$ purity ammonium hexafluorotitanate $\left(\mathrm{NH}_{4}\right)_{2} \mathrm{TiF}_{6}(\mathrm{AHFT})$, boric acid (BA), and $98 \%$ purity strontium nitrate (SN). First, these compounds were dissolved into deionized water separately. Then, a homogenous solution was made by mixing them together. The concentrations of the three substances in the solution were $25 \mathrm{mM}$ AHFT, $25 \mathrm{mM} \mathrm{SN}$, and $75 \mathrm{mM}$ BA, respectively. 
Thus, the molar ratios were kept as AHFT:SN:BA = 1:1:3. Deposition of the solid phase was achieved by contacting one side of a p-type silicon wafer with the top surface of the solution. The deposition process was carried out at $50{ }^{\circ} \mathrm{C}$ for 3 to $4.5 \mathrm{~h}$. The as-deposited thin film was amorphous, but it can be converted into the crystallized STO through annealing in air at $500{ }^{\circ} \mathrm{C}$ for $2 \mathrm{~h}$.

Koumoto et al. [88] showed their work on micropatterning of titanium dioxide on self-assembled monolayers using the liquid-phase deposition (LPD) technique. Figure 4 shows the image and the composition profile of liquid phase deposited titanium dioxide micropatterns [88]. Figure 4a illustrates the edge roughness of the pattern. Figure $4 \mathrm{~b}$ is the energy dispersive $\mathrm{X}$-ray diffraction map, showing the titanium element signal. The bright areas (hydrophilic regions) correspond to deposited $\mathrm{TiO}_{2}$. The absence of signal (corresponding to the instrument noise level) in the dark areas (hydrophobic regions) signifies the complete removal of $\mathrm{TiO}_{2}$ following sonication [88]. Pure $\mathrm{TiO}_{2}$ self-assembling coatings can be made by the liquid phase deposition technique using the following similar starting materials: ammonium hexafluorotitanate $\left(\mathrm{NH}_{4}\right)_{2} \mathrm{TiF}_{6}$ (AHFT), boric acid (BA), and water as shown in more details in [88].
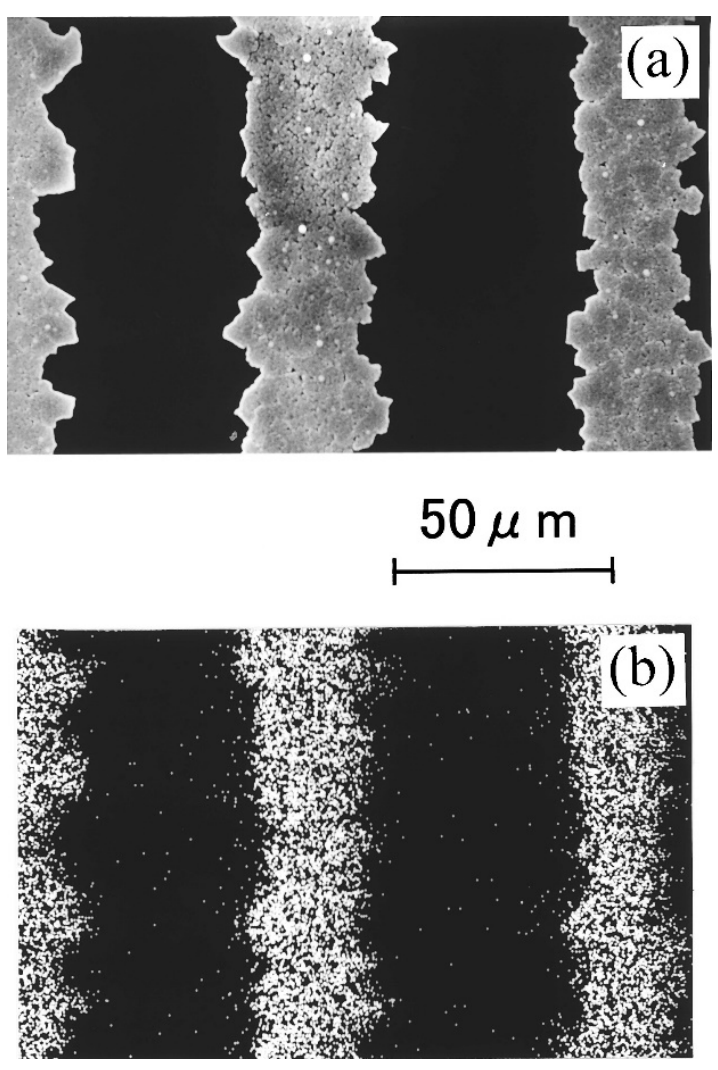

Figure 4. (a) SEM image of nominal $25-\mu \mathrm{m} \mathrm{TiO}_{2}$ lines from liquid phase deposition, and (b) the corresponding EDX Ti X-ray map image confirming the selective deposition of $\mathrm{TiO}_{2}$ on the patterned surface. Reprinted with permission from [88], (C) 1999, American Chemical Society.

Metallic nanoparticles may be co-deposited into the $\mathrm{TiO}_{2}$ films. As reported by Deki et al. [89], gold dispersed titanium dioxide coatings were prepared by the liquid phase deposition. It is also possible to synthesize $\mathrm{Si}_{(1-x)} \mathrm{Ti}_{x} \mathrm{O}_{2}$ thin films with gradient composition profiles by liquid phase deposition [87]. The complex oxides were obtained by deposition from the solution which was made by dissolving multiple compounds in a concentrated HF aqueous solution. A very similar example for deposition of multicomponent coatings such as $(\mathrm{La}, \mathrm{Sr}) \mathrm{MeO}_{3}(\mathrm{Me}=\mathrm{Cr}, \mathrm{Mn}, \mathrm{Fe}$, and $\mathrm{Co})$ can be found in the work performed by Yao et al. [86]. First, the ( $\mathrm{La}, \mathrm{Sr}) \mathrm{MeO}_{3}$ solid was prepared by powder sintering. Then, the powder product was dissolved in hydrofluoric acid to produce 
fluorocomplexes. Then, boric acid was added to the solution to form $\mathrm{BF}_{4}{ }^{-}$. The boric acid induced reaction and consumed the fluoride ions effectively. Consequently, the metal fluorocomplexes were hydrolyzed to produce the ( $\mathrm{La}, \mathrm{Sr}) \mathrm{MeO}_{3}$ solid. X-ray diffraction experiments confirmed that the structure of the resulted ( $\mathrm{La}, \mathrm{Sr}) \mathrm{MeO}_{3}$ coatings showed the high crystallinity of a solid solution.

$\mathrm{Su}$ et al. [91] prepared a heterogeneous thermoelectric nanocomposite with a $\mathrm{TiO}_{2}$ sheath coating on a $\mathrm{CoO}$ nanotube core by the liquid phase deposition technique. First, the $\mathrm{TiO}_{2}$ coating was deposited on the inner walls of the pores within an anodic aluminum oxide (AAO) membrane with a pore diameter of $20 \mathrm{~nm}$. Before the deposition of the $\mathrm{TiO}_{2}$ nanocoating via liquid phase deposition (LPD), both sides of the AAO membrane were covered with a self-assembled monolayer to prevent the deposition of the $\mathrm{TiO}_{2}$ particles on the top and bottom surfaces of the AAO membrane. Consequently, the $\mathrm{TiO}_{2}$ nanocoating only formed on the inner walls of the nanopores rather than on the two flat surfaces of the AAO membrane. The self-assembled monolayer was prepared by mixing $10 \mathrm{mM}$ octadecyltetrachlorosilane in $50 \mathrm{~mL}$ of hexane solution. After that, a layer of the $\mathrm{TiO}_{2}$ nanocoating was generated by immersing the treated $\mathrm{AAO}$ membrane with the monolayer into $10 \mathrm{~mL}$ of a mixed aqueous solution containing $0.05 \mathrm{M}\left(\mathrm{NH}_{4}\right)_{2} \mathrm{TiF}_{6}$ and $0.1 \mathrm{M} \mathrm{H}_{3} \mathrm{BO}_{3}$ for about $30 \mathrm{~min}$ to make sure that the $\mathrm{TiO}_{2}$ nanocoating within the nanopores reached the required thickness. The addition of the $\mathrm{H}_{3} \mathrm{BO}_{3}$ acid was found to accelerate the $\mathrm{TiO}_{2}$ deposition. The deposited AAO membrane was washed with deionized (DI) water several times and dried completely. The acquired AAO membrane was then heated at $550{ }^{\circ} \mathrm{C}$ for $2 \mathrm{~h}$. The heat treatment allowed the crystallization of $\mathrm{TiO}_{2}$ nanocoating. Figure 5 a provides a top view of the crystalized $\mathrm{TiO}_{2}$ nanocoating.

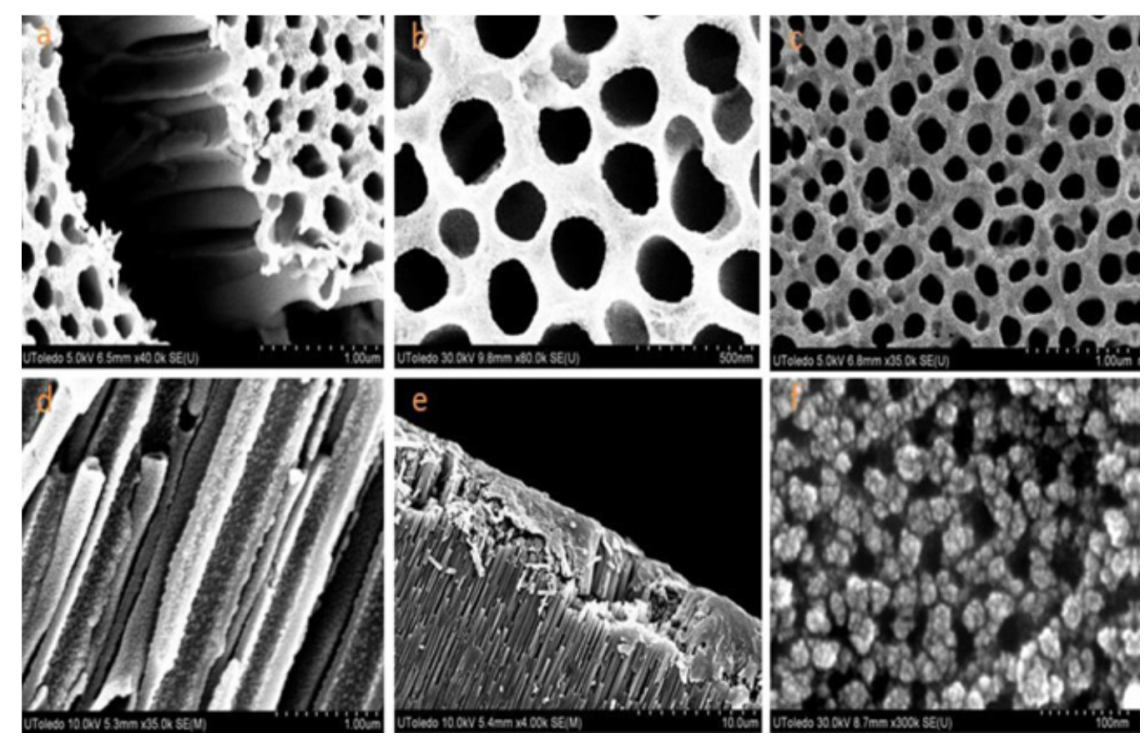

Figure 5. SEM images of (a) the top view of the $\mathrm{TiO}_{2}$ nanotubes, (b) the surface morphology of the $\mathrm{TiO}_{2}$ nanotubes and $\mathrm{Ag}$ particles, (c) the top view of the $\mathrm{CoO}$ nanotubes, (d) the cross-section of the $\mathrm{TiO}_{2}-\mathrm{CoO}$ nanocables, and (e) the cross-section of the $\mathrm{TiO}_{2}-\mathrm{CoO}$ nanocables after sputtering $\mathrm{Au}$ coating and (f) the top view of the $\mathrm{TiO}_{2}-\mathrm{CoO}$ nanocables after sputtering Au coating. Reproduced with permission from [91], (C) 2010, Elsevier B.V.

To promote the hydrolysis of the $\left(\mathrm{NH}_{4}\right)_{2} \mathrm{TiF}_{6}$ compound, the fluorine ions in the solution should be consumed to ensure the formation of the $\mathrm{TiO}_{2}$. The added boric acid exactly served the role of fluorine ion scavenger. In order to enhance the thermoelectric performance of the composite material, Ag precipitations were generated and placed into the $\mathrm{TiO}_{2}$ nanotubes to reduce the electrical resistivity. To generate fine Ag nanoparticles and make sure they are dispersed uniformly on the inner wall of the $\mathrm{TiO}_{2}$ nanotubes, $\mathrm{TiO}_{2}$-AAO was dipped into $10 \mathrm{~mL}$ of $0.05 \mathrm{M} \mathrm{AgNO}_{3}$ solution. After being washed with DI 
water and dried, it was heated at $500{ }^{\circ} \mathrm{C}$ for $1 \mathrm{~h} . \mathrm{AgNO}_{3}$ decomposed and produced $\mathrm{Ag}$ nanoparticles (NPs). These particles are distributed uniformly into the inner wall of the $\mathrm{TiO}_{2}$ nanotubes. Figure $5 \mathrm{~b}$ provides the top view of the silver nanoparticle-containing $\mathrm{TiO}_{2}$ nanotubes (NTs). The Ag particles may not be easily seen due to their tiny sizes.

The deposition of the $\mathrm{CoO}$ inside the $\mathrm{TiO}_{2}$ followed the steps as described below. A self-assembled monolayer was applied again to prevent the uneven deposition of $\mathrm{CoO}$ on the top and bottom surfaces of the AAO template decorated with $\mathrm{TiO}_{2}$ in the form of thin walled nanotubes (NTs) and/or Ag (NPs). The self-assembled monolayer was the same as mentioned above. The AAO template with $\mathrm{TiO}_{2}$ nanocoating and/or $\mathrm{Ag}$ (NPs) was immersed into $10 \mathrm{~mL}$ solutions of $0.05 \mathrm{M} \mathrm{Co}\left(\mathrm{NO}_{3}\right)_{2}$ for $20 \mathrm{~min}$ to obtain $\mathrm{TiO}_{2}-\mathrm{Ag}-\mathrm{CoO}$ nanocables. After the $\mathrm{Co}^{2+}$ ions and $\mathrm{NO}_{3}{ }^{-}$ions were impregnated into the $\mathrm{TiO}_{2}$ nanotubes, the template was air-dried. Then, it was heated at $450{ }^{\circ} \mathrm{C}$ for $30 \mathrm{~min}$ to obtain $\mathrm{CoO} @ \mathrm{TiO}_{2}$ bilayer nanotubes. This method can be used to deposit pore $\mathrm{CoO}$ thin layer into the inner wall of pores in AAO. The $\mathrm{CoO}$ nanotubes within the AAO were observed and an SEM image is shown in Figure $5 \mathrm{c}$. The top view of the specimen presents the structure with a fairly smooth surface. The cross section view of the $\mathrm{CoO} @ \mathrm{TiO}_{2}$ bilayer nanotubes can be found in Figure $5 \mathrm{~d}$. These nanotubes have a core/shell nanocable structure with some precipitates inside the wall of the pores. After the $\mathrm{CoO} @ \mathrm{TiO}_{2}$ bilayer nanotube sample was sputtering coated with $\mathrm{Au}$ thin film, the side view was shown in Figure 5e, and the top surface of the Au-coated $\mathrm{CoO} @ \mathrm{TiO}_{2}$ bilayer nanotube specimen was revealed in Figure 5f [91].

It must be noted that, by dissolving the $\mathrm{AAO}$ template into the solution with $\mathrm{H}^{+}$and $\mathrm{F}^{-}$ions, the $\mathrm{TiO}_{2}-\mathrm{CoO}$ nanocables can be released. The dissolution of the AAO substrate in the solution follows the reaction described in [91]. Figure 6 shows the high-resolution transmission electron microscopic (TEM) images. In Figure $6 \mathrm{a}$, the $\mathrm{TiO}_{2}$ nanotubes without the high temperature heat treatment are shown. Figure $6 \mathrm{~b}$ reveals the diffraction pattern of the heat treated $\mathrm{TiO}_{2}$ nanotubes. As can be seen from the diffraction pattern that the untreated tubes are amorphous. In Figure $6 \mathrm{c}$, the TEM image of the heat treated $\mathrm{TiO}_{2}-\mathrm{CoO}$ nanocables is shown, and Figure $6 \mathrm{~d}$ represents the diffraction pattern of the heat treated $\mathrm{TiO}_{2}-\mathrm{CoO}$ nanocables. Obviously, crystallization during the high temperature treatment on the $\mathrm{TiO}_{2}$ and $\mathrm{CoO}$ happened because the selected X-ray diffraction pattern came from crystalline phase or phases [91].

To measure the Seebeck coefficients of the $\mathrm{TiO}_{2}-\mathrm{CoO}$ nanocomposite samples, the two ends of each sample were bonded to strips of $\mathrm{Al}$ foils using a silver-based conductive adhesive. The aluminum foil strips can provide good conductive property at the composite/electrode interfaces. One end of the $\mathrm{Al}$ foil as the hot end was heated up to a required temperature. The hot end temperature ranged from 40 to $130^{\circ} \mathrm{C}$ in the experiments. The other end (cold end) was kept at the ambient temperature of $25^{\circ} \mathrm{C}$ [91]. The Seebeck coefficients at different temperatures were calculated for the four AAO-based nanocomposite specimens (named $\mathrm{TiO}_{2}, \mathrm{CoO}, \mathrm{TiO}_{2} / \mathrm{Ag}$ and $\mathrm{TiO}_{2} / \mathrm{Ag} / \mathrm{CoO}$ ) [91]. The calculated results, as listed in Table 1, show that the $\mathrm{AAO}-$ based $\mathrm{TiO}_{2}+\mathrm{Ag}$ has the highest absolute value of Seebeck coefficient, which may be due to the enhanced electrical property due to the incorporation of the Ag nanoparticles. These highly conductively metallic nanoparticles possess a high density of electrons under thermal excitation. In addition, the electron tunneling exists among the fine $\mathrm{Ag}$ nanoparticles within the nanotubes, which could improve the electrical conductivity of the nanocomposite significantly. The AAO-based $\mathrm{CoO}$ tube composite showed the lowest absolute value of Seebeck coefficient. This could be due to the semiconductor type change of $\mathrm{CoO}$. As known, $\mathrm{CoO}$ shows n- to p-type transition behavior, while the $\mathrm{TiO}_{2}$ nanotube is n-type. Another reason could be the reduced electrical conductivity of the $\mathrm{CoO} @ \mathrm{TiO}_{2}$ nanocable as compared with the $\mathrm{TiO}_{2}$ nanotube. The positive influence of $\mathrm{Ag}$ nanoparticles was found to be more intensive than the negative effect of the $\mathrm{CoO}$ for the Seebeck coefficient. This is why the $\mathrm{AAO}-$ based $\mathrm{TiO}_{2} / \mathrm{Ag} / \mathrm{CoO}$ nanocomposite has a higher absolute Seebeck coefficient value than the AAO-based $\mathrm{TiO}_{2}$ nanocomposite. In view of the absolute values of the Seebeck coefficients, the nanocomposites are ranked from high to low as follows: $\mathrm{TiO}_{2} / \mathrm{Ag}>\mathrm{TiO}_{2} / \mathrm{Ag} / \mathrm{CoO}>\mathrm{TiO}_{2}>\mathrm{CoO}$. It is concluded 
that the oxide-based nanocomposites containing $\mathrm{TiO}_{2}$ nanotubes and $\mathrm{CoO} @ \mathrm{TiO}_{2}$ coaxial nanocables possess strong Seebeck effect. The absolute value of the Seebeck coefficient for the $\mathrm{TiO}_{2}$ nanotube-filled AAO is $393 \mu \mathrm{V} / \mathrm{K}$, while the $\mathrm{CoO} @ \mathrm{TiO}_{2}$ coaxial nanocable-filled $\mathrm{AAO}$ has the slightly lower absolute value of $300 \mu \mathrm{V} / \mathrm{K}$. Both composites are n-type. The thermoelectric figure of merit of such nanocomposites could potentially be very high due to the low thermal conductivity value of the AAO matrix [91].
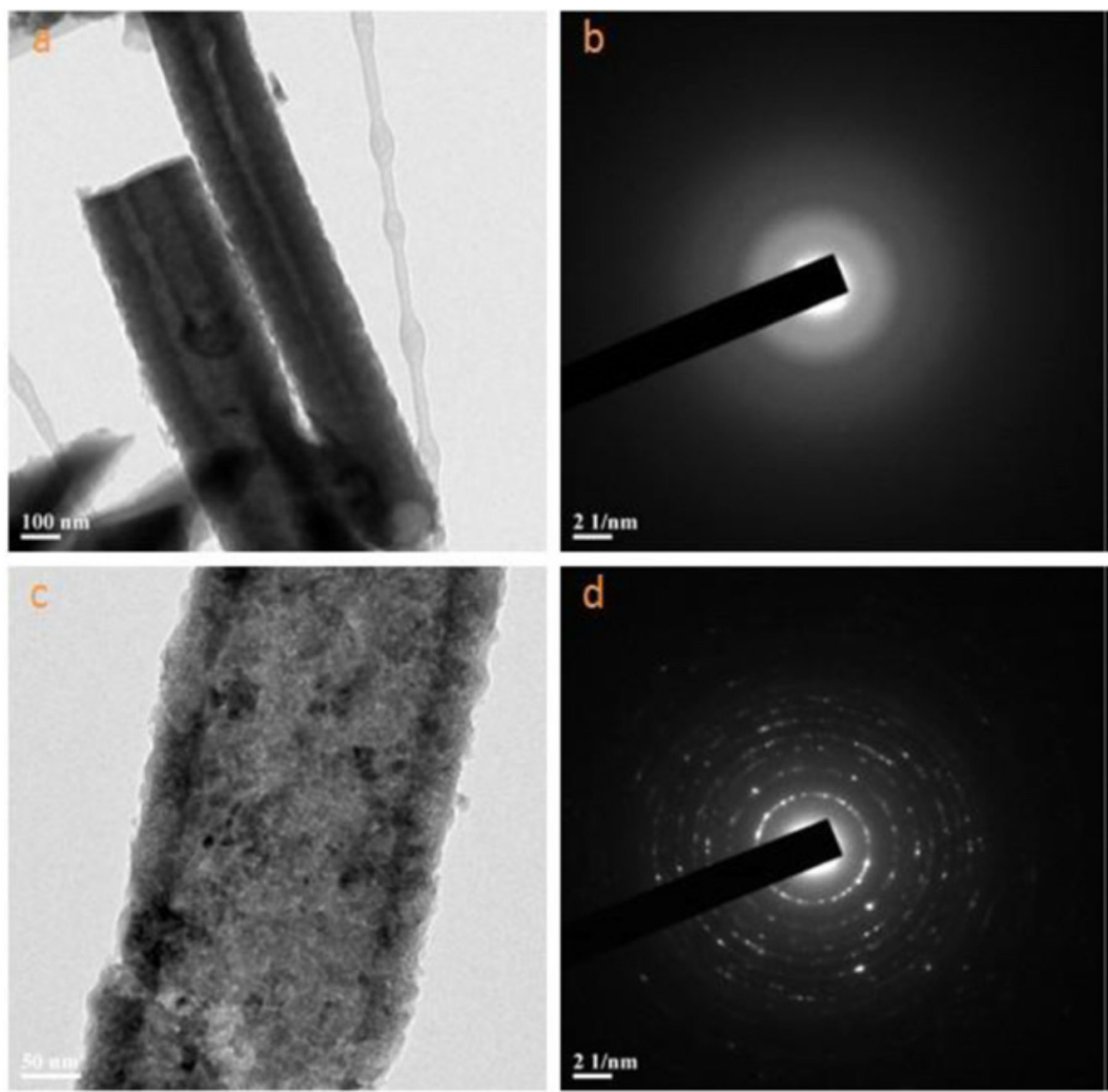

Figure 6. TEM images showing (a) $\mathrm{TiO}_{2}$ nanotubes, (b) the diffraction pattern of the $\mathrm{TiO}_{2}$ nanotubes, (c) $\mathrm{TiO}_{2}-\mathrm{CoO}$ nanocables, and (d) diffraction pattern of the $\mathrm{TiO}_{2}-\mathrm{CoO}$ nanocables. Reproduced with permission from [91], (C) 2010, Elsevier B.V.

Table 1. Seebeck coefficients of liquid phase deposited thermoelectric nanocomposites.

\begin{tabular}{ccccc}
\hline Temperature & $\mathrm{TiO}_{2}(\mu \mathrm{V} / \mathrm{K})$ & $\mathrm{CoO}$ & $\mathrm{TiO}_{2}+\mathbf{A g}$ & $\mathrm{TiO}_{2}+\mathbf{A g}+\mathbf{C o O}$ \\
\hline$\Delta V / \Delta T @ 40{ }^{\circ} \mathrm{C}$ & -220 & -93.33 & -393.33 & -300 \\
\hline$\Delta V / \Delta T @ 45^{\circ} \mathrm{C}$ & -210 & -90 & -320 & -255 \\
\hline$\Delta V / \Delta T @ 50{ }^{\circ} \mathrm{C}$ & -172 & -68 & -296 & -208 \\
\hline$\Delta V / \Delta T @ 55^{\circ} \mathrm{C}$ & -153.33 & -80 & -316.67 & -200 \\
\hline$\Delta V / \Delta T @ 60^{\circ} \mathrm{C}$ & -125.71 & -71.43 & -274.29 & -162.86 \\
\hline$\Delta V / \Delta T @ 70^{\circ} \mathrm{C}$ & -106.67 & -66.67 & -266.67 & -166.67 \\
\hline$\Delta V / \Delta T @ 80^{\circ} \mathrm{C}$ & -98.18 & -60 & -245.45 & -129.09 \\
\hline$\Delta V / \Delta T @ 90^{\circ} \mathrm{C}$ & -101.54 & -60 & -27.69 & -113.85 \\
\hline$\Delta V / \Delta T @ 110^{\circ} \mathrm{C}$ & -78.82 & -56.47 & -207.06 & -108.24 \\
\hline$\Delta V / \Delta T @ 130^{\circ} \mathrm{C}$ & -90.48 & -34.29 & -153.33 & -107.62 \\
\hline
\end{tabular}

Reproduced with permission from [91], (c) 2010, Elsevier B.V. 


\subsection{Nanocasting}

Nanocasting is a template-assisted solution approach. It is a powerful method for creating nanomaterial coatings that are more difficult to synthesize by conventional processes. This method can be briefly described as follows. A sacrificial template with desired backbones or nanostructures as the physical mold for casting is filled with a precursor material. Then, the sacrificial template is etched away by a chemical or removed by post heat treatment. Generally, two kinds of templates, hard and soft templates, are used in nanocasting processes. Hard templates can be made from silica, alumina, and carbon-based materials. While soft templates are generally polymer-based materials such as polycarbonate (PC) and Nylon. One of the advantages of nanocasting is that by meticulous selection of the template, it is convenient to produce oxide coatings with new compositions, structures, and demanded performances.

Chen et al. [92] used the nanocasting technique to prepare cobalt oxide nanostructures. The hard template: silica, was made from an ordered polymeric carbon replica. Significant reduction in the thermal conductivity of $\mathrm{Co}_{3} \mathrm{O}_{4}$ with ordered mesoporous structures was confirmed. Both nanocasting procedures by the use of the template (KIT-6) and the transport behavior of various cobalt oxide specimens are shown in Figure 7 [92]. The inset (a) represents the electrical conductivity change under different testing temperature conditions, and the inset (b) shows the thermal conductivity variation with the testing temperature. One of the cobalt oxide compound samples named $\mathrm{Co}_{3} \mathrm{O}_{4}-70$ shows the giant reduction in thermal conductivity, which is good for enhancing the thermoelectric figure of merit.

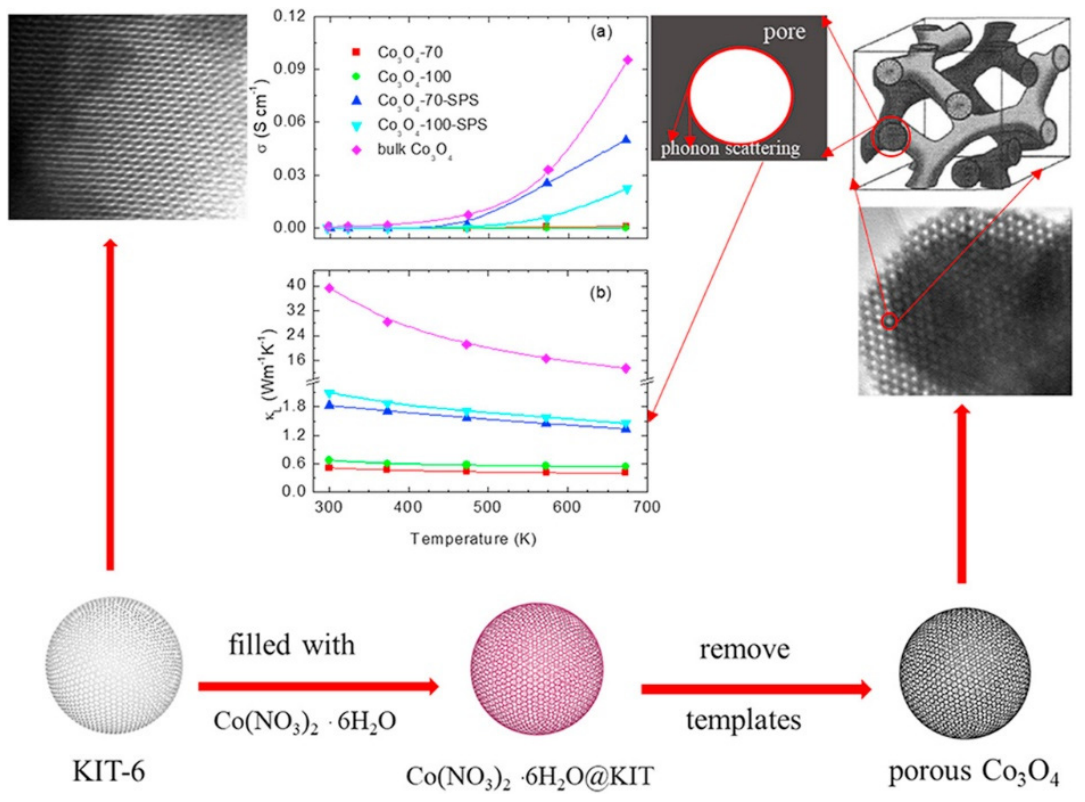

Figure 7. Procedures for nanocasting cobalt oxide and its electrical and thermal conductivities: (a) electrical conductivity, and (b) thermal conductivity. Reproduced with permission from [92], (c) 2019, Elsevier Inc.

Procedures for synthesizing the hard template are described following the method as reported by Zhou et al. [93]. In brief, the amphiphilic triblock copolymer Pluronic (P-123) was dissolved in distilled water containing $\mathrm{HCl}$. Following that, $\mathrm{n}$-butanol was added. Then, this mixture was stirred for $1 \mathrm{~h}$ at $35{ }^{\circ} \mathrm{C}$ before tetraethyl orthosilicate (TEOS, $\mathrm{C}_{8} \mathrm{H}_{20} \mathrm{O}_{4} \mathrm{Si}$ ) was added into the homogeneous clear solution. This mixture was further stirred at $35{ }^{\circ} \mathrm{C}$ for $24 \mathrm{~h}$. After that, it was transferred into two stainless-steel autoclaves which were sealed and aged at two different temperatures $\left(70\right.$ and $100{ }^{\circ} \mathrm{C}$, respectively) for $24 \mathrm{~h}$. The resulted mixtures were filtered several times. Being washed by water and air dried at $100{ }^{\circ} \mathrm{C}$, the obtained powders were further calcined at $550{ }^{\circ} \mathrm{C}$ for 
$6 \mathrm{~h}$ in air to remove the carbon-based polymer residues. The produced mesoporous silica templates were subjected to aging at 70 and $100^{\circ} \mathrm{C}$ and named as KIT-6-70 and KIT-6-100, respectively. It must be indicated that the Pluronic ( $\mathrm{P}-123)$ is a symmetric linear triblock copolymer consisting of poly(ethylene oxide) (PEO) and poly(propylene oxide) (PPO) aligned in an alternating way, i.e., $(\mathrm{PEO})_{x}-(\mathrm{PPO})_{y}-(\mathrm{PEO})_{z}$. The PPO block has a unique characteristic of showing hydrophobicity at temperatures above $15^{\circ} \mathrm{C}$ and solubility in water at temperatures below $15^{\circ} \mathrm{C}$. This leads to the formation of micelle consisting of PEO-PPO-PEO triblock copolymers. The hydrophobic core contains PPO block, and the hydrophilic corona consists of PEO block. If the concentration of the P-123 in water is carefully controlled, the desired cubic gelation phase could be obtained. For example, a $30 \mathrm{wt}$ \% aqueous solution of Pluronic P-123 allows the formation of a cubic gelation phase to hold the silica-based compound, tetraethyl orthosilicate, in its open space.

Then, the mesoporous $\mathrm{Co}_{3} \mathrm{O}_{4}$ was synthesized using the prepared KIT-6-70 or KIT6-100 template [93]. As also shown in [94], the nitrate compound $\mathrm{Co}\left(\mathrm{NO}_{3}\right)_{2} \cdot 6 \mathrm{H}_{2} \mathrm{O}$ was used as the precursor. The as-synthesized KIT-6-70 or KIT-6-100 was suspended in the linear chain liquid hexane or $n$-hexane. The cobalt nitrate aqueous solution was added dropwise under vigorous stirring. The mixture was continuous stirred until the n-hexane volatilized completely. After the mixture dried at room temperature overnight, a pink powder was obtained. The powder specimen was calcined at different temperatures such as 300,500 , and $550{ }^{\circ} \mathrm{C}$ for $5 \mathrm{~h}$. The high temperature calcination caused the nitrate to decompose completely and was converted into cobalt oxide. The silica template was then removed by etching twice with $2.0 \mathrm{M}$ warm $\mathrm{NaOH}$ aqueous solution for $12 \mathrm{~h}$ each time. The template-free mesoporous $\mathrm{Co}_{3} \mathrm{O}_{4}$ was collected by centrifugation. After that, it was washed with deionized water to neutral. The neutral powder was completely dried at $100{ }^{\circ} \mathrm{C}$. This mesoporous $\mathrm{Co}_{3} \mathrm{O}_{4}$ prepared by nanocasting was used as the raw material for making thermoelectric specimens after the completion of various post processing and manufacturing processes. One of the processes was cold pressing into pellets at the room temperature under a pressure of $10 \mathrm{MPa}$ for $10 \mathrm{~min}$. Then the pellets were consolidated by spark plasma sintering (SPS) at $550{ }^{\circ} \mathrm{C}$ under a pressure of $100 \mathrm{MPa}$. In another case of post processing, the $\mathrm{Co}_{3} \mathrm{O}_{4}$ powder was directly spark plasma sintered. The samples from both post treatment processes were studied for thermoelectric energy conversion. Comparative study on the thermal conductive behavior of the bulk cobalt oxide and nanocast one was made as well. It is found that the bulk $\mathrm{Co}_{3} \mathrm{O}_{4}$ has the thermal conductivity as high as $39.3 \mathrm{~W} /(\mathrm{m} \cdot \mathrm{K})$ at the room temperature [92]. While a typical nanocast $\mathrm{Co}_{3} \mathrm{O}_{4}$ sample shows the thermal conductivity as low as $0.51 \mathrm{~W} /(\mathrm{m} \cdot \mathrm{K})$ as shown by the inset (b) in Figure 7 [92]. Such a dramatic reduction in the thermal conductivity should be very helpful for increasing the thermoelectric figure of merit, $z \mathrm{~T}$, of the $\mathrm{Co}_{3} \mathrm{O}_{4}$ material.

\subsection{Solid-State Processing}

Solid state processing has been widely used to make thermoelectric oxide materials [44,84-98]. Diez et al. [44] made the $\mathrm{Ca}_{3} \mathrm{Co}_{(4-x)} \mathrm{Cr}_{x} \mathrm{O}_{9}$ polycrystalline thermoelectric oxide materials with small amounts of $\mathrm{Cr}$. The solid-state processing method can be briefly summarized as follows, taking $\mathrm{Ca}_{3} \mathrm{Co}_{(4-x)} \mathrm{Cr}_{x} \mathrm{O}_{9}(x=0.00,0.01,0.03,0.05$, and 0.10) as examples as described in [44]. The polycrystalline oxide materials were made from the carbonate and oxide compounds such as $\mathrm{CaCO}_{3}, \mathrm{Co}_{2} \mathrm{O}_{3}$, and $\mathrm{Cr}_{2} \mathrm{O}_{3}$. Appropriate amount of each compound powder was weighed, well mixed, and ball milled in the acetone medium. The obtained slurry was heated using infrared radiation to remove the acetone. The dry mixture was milled again under dry condition to prevent any powder aggregations. Then, the mixture was heat treated twice in air at 750 and $800{ }^{\circ} \mathrm{C}$, respectively, for $12 \mathrm{~h}$. An intermediate manual milling was used to assist the decomposition of $\mathrm{CaCO}_{3}$. After the heat treatment, the powder mixture was pressed at $400 \mathrm{MPa}$ shortly to generate green ceramic pellets. The pellets were further sintered at $900{ }^{\circ} \mathrm{C}$ for $24 \mathrm{~h}$ to form the specimens for thermoelectric property characterization. 
It is convenient to introduce additives or dopants into the base Ca-Co-O oxide through the solid-state processing route. Presečnik and Bernik [96] doped the $\mathrm{Ca}_{3} \mathrm{Co}_{4} \mathrm{O}_{9}$ oxide with $\mathrm{WO}_{3}$ by directly adding $\mathrm{WO}_{3}$ powder as one of the starting materials. Without increasing the sintering temperature for consolidating the green ceramic specimen, the $\mathrm{WO}_{3}$-doped $\mathrm{Ca}_{3} \mathrm{Co}_{4} \mathrm{O}_{9}$ oxide with good quality was obtained. The Seebeck effect coefficient was found to increase slightly from $147 \mu \mathrm{V} / \mathrm{K}$ for the un-doped oxide to $157 \mu \mathrm{V} / \mathrm{K}$ for the doped specimen. In addition, the thermal conductivity is significantly decreased from $1.15 \mathrm{~W} /(\mathrm{m} \cdot \mathrm{K})$ for the specimen without the $\mathrm{WO}_{3}$ dopant to $0.88 \mathrm{~W} /(\mathrm{m} \cdot \mathrm{K})$ for the $\mathrm{WO}_{3}$-doped $\mathrm{Ca}_{3} \mathrm{Co}_{4} \mathrm{O}_{9}$ oxide. Kahraman et al. [97] doped the $\mathrm{Ca}_{3} \mathrm{Co}_{4} \mathrm{O}_{9}$ oxide with silver. Before the solid-state processing, a sol-gel procedure was adopted to make the slurry containing silver nitrate. The same sintering temperature of $900{ }^{\circ} \mathrm{C}$ was used to form the Ag-doped $\mathrm{Ca}_{3} \mathrm{Co}_{4} \mathrm{O}_{9}$ for the thermoelectric property evaluation. It is found that the thermoelectric power factor was increased due to the silver doping. $\mathrm{PbO}$ was introduced into $\mathrm{Ca}_{3} \mathrm{Co}_{4} \mathrm{O}_{9}$ through the solid-state processing as shown by Demirel et al. [98]. With the $\mathrm{Pb}$-ion doping, the Seebeck effect coefficient of the specimen was increased to $200 \mu \mathrm{V} / \mathrm{K}$. The thermoelectric figure of merit, $z T$ value for the $\mathrm{Pb}$-doped specimen is about 16 times higher than that for the specimen without any $\mathrm{Pb}$ doping.

A modified solid-state processing method is shown in [47] by introducing pressureassisted sintering (PAS). During high temperature sintering, a pressure was added to the specimen to increase the density of the $\mathrm{Ca}_{3} \mathrm{Co}_{4} \mathrm{O}_{9}$ material. Better results were achieved by the PAS calcined sample. The dense and textured microstructure generated by PAS allows a high-power factor of $326 \mu \mathrm{W} /\left(\mathrm{m} \cdot \mathrm{K}^{2}\right)$ at $800{ }^{\circ} \mathrm{C}$. However, the adverse effect in view of the increase in thermal conductivity remains to be resolved.

Still another derived solid-state processing is mechanical exfoliation or peeling of bulk materials to form thin coatings. Although it is famous for making graphene, other low dimensional materials, for example, a p-type two dimensional $\mathrm{BiOBr}$ thermoelectric oxide as mentioned in [99] was also made by this approach.

Inverse perovskites, $\mathrm{Mg}_{3} \mathrm{SiO}$ and $\mathrm{Mg}_{3} \mathrm{GeO}, \mathrm{Ca}_{3} \mathrm{SiO}$ and $\mathrm{Ca}_{3} \mathrm{GeO}$ are considered as promising thermoelectric oxide materials with good performance as indicated by the computational results [100]. The computed Seebeck coefficients are shown in Figure 8 for four types of inverse perovskites. The Boltzmann equations with a relaxation time limited by acoustic phonon scattering and a carrier concentration of $10^{20} \mathrm{~cm}^{-3}$ were used for the computation. $\mathrm{Ca}_{3} \mathrm{SiO}$ and $\mathrm{Ca}_{3} \mathrm{GeO}$ are caught particular interest. These two oxides were experimentally processed via solid-state reactions. In brief, the starting materials including $\mathrm{Ca}$ granules, $\mathrm{Si}$ powder, and $\mathrm{SiO}_{2}$ powder for $\mathrm{Ca}_{3} \mathrm{SiO}$ preparation; $\mathrm{Ca}$ granules, Ge ingot, and $\mathrm{GeO}_{2}$ powder for $\mathrm{Ca}_{3} \mathrm{GeO}$ formation were mixed, respectively, in an Ar-filled glovebox. To produce $\mathrm{Ca}_{3} \mathrm{SiO}$ and $\mathrm{Ca}_{3} \mathrm{GeO}$, the two different mixtures were placed in separated niobium tubes that were sealed by welding in $\mathrm{Ar}$ atmosphere. Each of the $\mathrm{Nb}$ tubes was inserted into a fused-silica tube. The silica tubes were then evacuated and sealed. To complete the solid-state reactions, the two mixtures were heated up to $1423 \mathrm{~K}$ over $11 \mathrm{~h}$ and kept at the temperature for 4 days. Then, the generated products were cooled down slowly at a rate of $3 \mathrm{~K} / \mathrm{min}$ to $1073 \mathrm{~K}$. After that, they were kept at the temperature (1073 K) for 2 days. Finally, they were cooled down to the room temperature over $8 \mathrm{~h}$. The obtained samples are gray powders that are moisture- and air-sensitive. The powder samples were cold-pressed into $\mathrm{Ca}_{3} \mathrm{SiO}$ and $\mathrm{Ca}_{3} \mathrm{GeO}$ pellets. The consolidated pellets were adhered between two gold-plated copper disks with silver epoxy. The electrical resistivity and the thermal conductivity were determined from the electrical resistance and the thermal conductance, respectively. The thermal conductivity was corrected assuming an emissivity of one due to blackbody radiation. The Seebeck coefficient was calculated from the voltage drop by applying a temperature gradient. Figure 9 shows the measured results of electrical resistivity, Seebeck coefficient, and thermal conductivity of the $\mathrm{Ca}_{3} \mathrm{SiO}$ and $\mathrm{Ca}_{3} \mathrm{GeO}$ specimens. It can be seen from the experimental results that these inverse perovskites demonstrate high Seebeck coefficients and low thermal conductivities. Both $\mathrm{Ca}_{3} \mathrm{SiO}$ and $\mathrm{Ca}_{3} \mathrm{GeO}$ have potential for practical thermoelectric applications. 

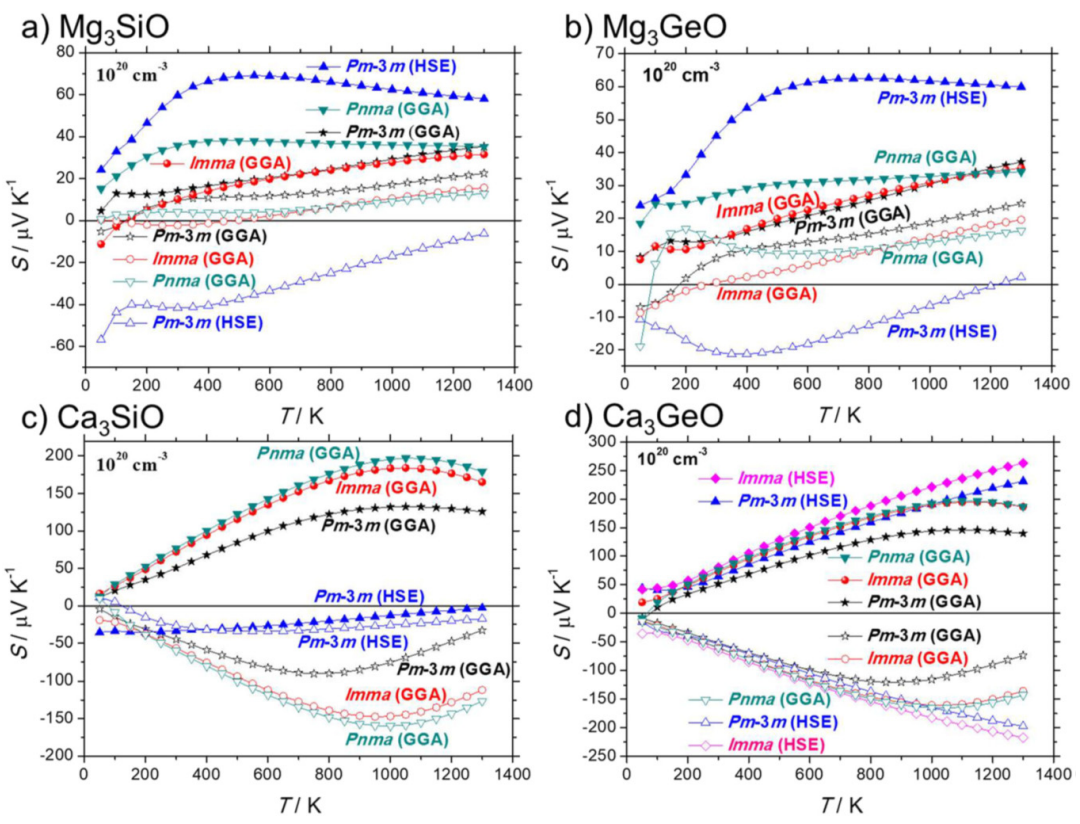

Figure 8. Computed Seebeck coefficients for (a) $\mathrm{Mg}_{3} \mathrm{SiO}$, (b) $\mathrm{Mg}_{3} \mathrm{GeO}$, (c) $\mathrm{Ca}_{3} \mathrm{SiO}$, and (d) $\mathrm{Ca}_{3} \mathrm{GeO}$ assuming p-type (solid symbols) or n-type carriers (open symbols). Reproduced from [100], (C 2019, the authors.

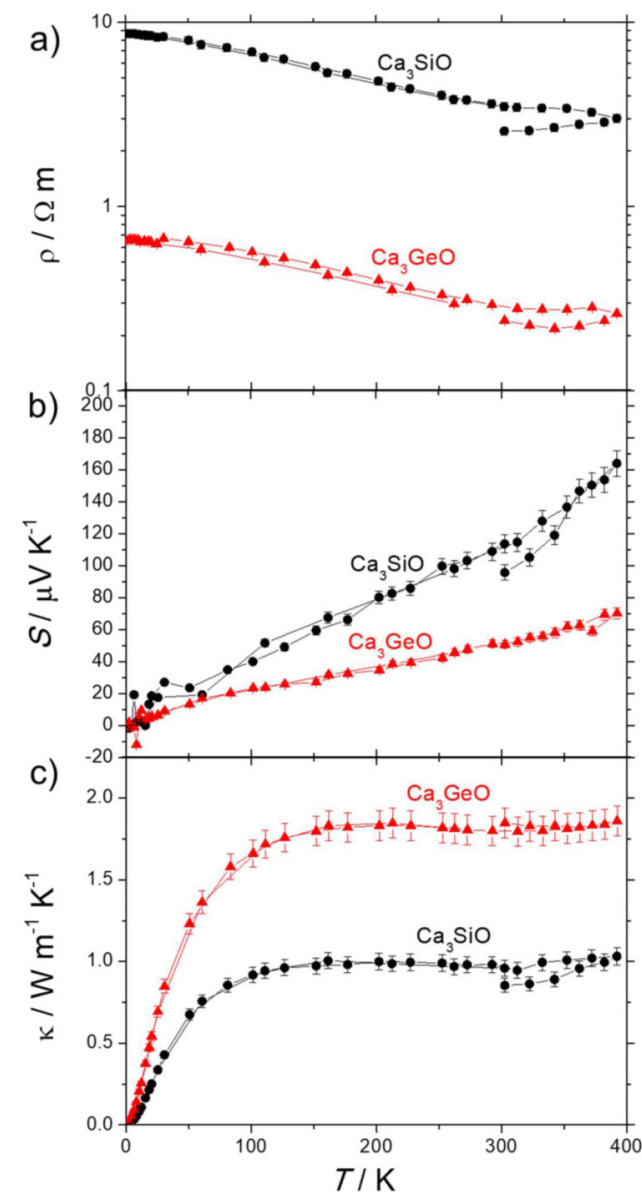

Figure 9. Experimental measurements of (a) electrical resistivity, (b) Seebeck coefficient, and (c) thermal conductivity for orthorhombic $\mathrm{Ca}_{3} \mathrm{SiO}$ and $\mathrm{Ca}_{3} \mathrm{GeO}$. Reproduced from [100], (c) 2019, the authors 
In order to prepare the precursors for solid state processing, a solution-based method followed by self-propagating combustion was adopted in the work performed by Madre et al. [101]. First, synthesis of Bi-Sr-Co-O precursors was carried out by making an acetic solution using glacial acetic acid and metallic acetates as the starting materials. Then, polyethyleneimine (PEI) was added (with the mole ratio of PEI to $\mathrm{Bi}_{2} \mathrm{Sr}_{2} \mathrm{Co}_{1.8} \mathrm{O}_{x}=1: 2$ ) into the solution, resulting in the cation-nitrogen coordination. After air dried, a dark pink thermoplastic paste was obtained. The mixture was baked at $50{ }^{\circ} \mathrm{C}$ to change into violet color. Then it was heated up to 300 to $350^{\circ} \mathrm{C}$ to initiate the self-propagating combustion. The combustion allowed the temperature to go up to $750{ }^{\circ} \mathrm{C}$. The dark powder product was collected for the subsequent solid-state processing including pulverizing, pressing and sintering.

Sotelo et al. [102] synthesized the $\mathrm{Bi}_{2} \mathrm{Ca}_{2} \mathrm{Co}_{1.7} \mathrm{O}_{x}$ based thermoelectric oxide by different methods including the solid-state route, sol-gel synthesis, and the polymer approach. In the solid-state processing, $\mathrm{Bi}_{2} \mathrm{O}_{3}, \mathrm{CaCO}_{3}$, and $\mathrm{Co}_{3} \mathrm{O}_{4}$ were ball-milled first. Then the mixture was heat treated at $750{ }^{\circ} \mathrm{C}$ for $12 \mathrm{~h}$. After that, the powder was cooled down and grounded. The grounded powder was heat treated again at $800{ }^{\circ} \mathrm{C}$ for $12 \mathrm{~h}$. Then the powder was milled again and pressed at $250 \mathrm{MPa}$ into pellets. Lastly, the pellets were sintered at $800{ }^{\circ} \mathrm{C}$ for $24 \mathrm{~h}$ to form the $\mathrm{Bi}_{2} \mathrm{Ca}_{2} \mathrm{Co}_{1.7} \mathrm{O}_{x}$ based thermoelectric oxide specimens. The sol-gel synthesis used nitrates to make slurry for self-propagating combustion. The obtained mixture was cold-pressed and sintered at the high temperature of $800^{\circ} \mathrm{C}$ to get the $\mathrm{Bi}_{2} \mathrm{Ca}_{2} \mathrm{Co}_{1.7} \mathrm{O}_{x}$. In the polymer approach, the process of cation-nitrogen coordination by polyethyleneimine (PEI) polymer was used as described in [102]. The preparation of the final product $\left(\mathrm{Bi}_{2} \mathrm{Ca}_{2} \mathrm{Co}_{1.7} \mathrm{O}_{x}\right)$ also relies on the solid-state processing. Comparative studies of the three synthesis routes revealed that the solid-state method resulted in a fairly good $\mathrm{Bi}_{2} \mathrm{Ca}_{2} \mathrm{Co}_{1.7} \mathrm{O}_{x}$ product. However, the sol-gel method allowed much higher yields of the cobaltite phase. Therefore, improved thermoelectric properties were observed. The polymer-based route was considered as the best way regarding to the structural homogeneity and enhanced $z T$ value. The increase in the $z T$ value was believed due to the reduction of secondary phases, the complexity of grain shape, and the high oxygen vacancies generated through the polymer approach.

\subsection{Energy Beam Techniques}

Energy beam techniques include plasma deposition, electron beam (e-beam or EB) processing, ion-beam injection/deposition, pulsed laser deposition (PLD), and laser-assisted catalytic growth. The bombardment of energy beams vaporizes materials from targets. The vaporized materials subsequently deposit on substrates. The facilities for energy beam-assisted processing typically include a beam source and all the other components as found for vapor deposition $[72,103]$. The target materials could be pure metals, metallic alloys, polymers, and ceramics [104]. Sometimes more than one target may be used simultaneously to deposit multilayered complex coatings. For example, Jones et al. [104] deposited layered oxide materials having alternating repeated layer thicknesses of $10 \mathrm{~nm}$ or less. Such complex and fine structures with sharp interfaces are usually hard to fabricate. Nanostructured oxide thin films with repeated layers of two different oxide materials were generated by pulsed-laser deposition during which two independent stationary targets consisting of $\mathrm{Al}_{2} \mathrm{O}_{3}$ and $\mathrm{BaTiO}_{3}$ were used [104]. The deposition rate of PLD varies with the types of beam, atmosphere in the chamber, temperature of the substrate, the magnitude of the laser power, and the oxygen background gas pressure level in the chamber [105].

Among various energy beam techniques, pulsed laser deposition is considered as a powerful tool. Pulsed laser deposition (PLD) is classified as one of the physical vapor deposition (PVD) techniques. Inside a vacuum chamber, a high-power and pulsed-laser beam bombasts a target of the material that is to be deposited. The material sublimates from the target in a plasma plume and deposits as a thin layer of coating on a substrate. The substrate may be a silicon wafer or a ceramic plate facing the target [106]. This process can be done in ultra-high vacuum or in the presence of a background gas, such as oxygen 
which is commonly used when depositing oxides to fully oxygenate the deposited coatings. Hydrogen and argon gases may also be used for LPD [107].

The physical phenomena of laser-target interaction and film growth are quite complex. When the laser pulse is absorbed by the target, energy is first converted to electronic excitation and then into thermal, chemical, and mechanical energy resulting in evaporation, ablation, plasma formation, and even exfoliation. The ejected species expand into the surrounding vacuum in the form of a plume containing many energetic species including atoms, molecules, electrons, ions, clusters, particulates and molten globules, before depositing on the typically hot substrate [108].

$\mathrm{SrTiO}_{3}$ coatings were prepared by pulsed laser deposition (PLD) [109,110]. Following the PLD, nitrogen ion implantation with the energy level of $60 \mathrm{keV}$ was carried out. Structure and transport behavior of the thin coatings were investigated. The local distortion of $\mathrm{TiO}_{6}$ octahedra and introduction of oxygen vacancies due to $\mathrm{N}$ implantation were confirmed by the X-ray absorption spectroscopy of the films. The temperature-dependent electrical and thermoelectric properties of these coatings were evaluated to understand the conduction and scattering mechanisms. Both electrical conductivity and Seebeck coefficient of these $\mathrm{SrTiO}_{3}$ thin films were significantly enhanced at high dosage of $\mathrm{N}$ ion implantation. The effect of temperature on the electrical resistivity was examined in the temperature range from 80 to $400 \mathrm{~K}$. Various conduction mechanisms were proposed to analyze the electrically conductive behavior. Data fitting with band conduction, near neighbor hopping $(\mathrm{NNH})$, and variable range hopping $(\mathrm{VRH})$ models was performed. It is found that the band conduction mechanism dominates in both high temperature regime and low temperature regime. The crossover between NNH and VRH was observed as well. The Seebeck coefficient, $S$, was estimated using the relaxation time approximation model and dispersive transport mechanism in the temperature range from 300 to $400 \mathrm{~K}$. It is revealed that the ion beam implantation enhances the electrical conductivity and thermopower of the coatings. The power factor is as high as $15 \mu \mathrm{W} /\left(\mathrm{m} \cdot \mathrm{K}^{2}\right)$ at $400 \mathrm{~K}$, which is much higher than that of the pristine $\mathrm{SrTiO}_{3}$ coatings. It is evident that the energy beam processing can improve the electrical transport properties of thermoelectric oxide coatings. The temperature-dependent electrical resistivity, $\rho$, of STO processed via PLD at 450,650 , and $750{ }^{\circ} \mathrm{C}$ (samples named as STO-450, STO-650, and STO-750) is shown in Figure 10a [110]. In Figure 10b, the logarithm of electrical resistivity is presented. From the results shown in Figure 10b, linear relations are revealed. This indicated that the STO samples of the conduction mechanism follow the thermally activated charge carriers, jumping from the localized states to the conduction band.
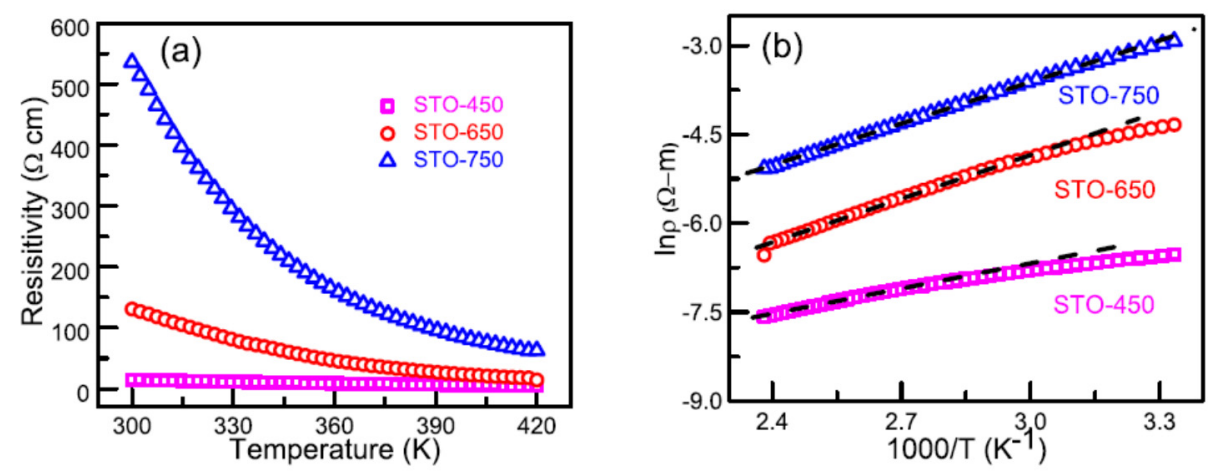

Figure 10. (a) Resistivity of STO thin films deposited at 450, 650, and $750{ }^{\circ} \mathrm{C}$ as a function of temperature, and (b) $\ln (\rho)$ vs. $1 / \mathrm{T}$ of STO-450, STO-650, and STO-750 films, respectively. The dashed black line represents the linear fit. Reproduced with permission from [110], (c) 2020, Elsevier B.V.

Electron beam irradiation changed the electrical transport properties of a polycrystalline $\mathrm{PrCoO}_{3}$ thermoelectric oxide in a different way as shown in [111]. The polycrystalline bulk samples of cobaltite $\mathrm{PrCoO}_{3}$ were irradiated by electron beam (EB) at room temperature for various dosages of 50, 100, and $200 \mathrm{kGy}$. A linear particle accelerator was 
used to carry out the EB irradiation. The beam energy of the used linear accelerator was $7.5 \mathrm{MeV}$ under the beam power of $1.5 \mathrm{~kW}$. Unlike the case for STO after ion beam implantation [109], the EB irradiation reduced the Seebeck coefficient of the $\mathrm{PrCoO}_{3}$ dramatically. The reason for this is that EB irradiation hinders the phonon drag.

Ion beam sputtering (IBS) is also called ion beam deposition (IBD) or ion beam sputtering deposition (IBSD). It is a thin coating deposition process that uses an ion source to deposit or sputter a target material (metal or dielectric) onto a substrate to create either a metallic or dielectric coating. Kennedy et al. [112] demonstrated that the ion beam method is a suitable approach to enhancing the thermoelectric properties of Al-doped $\mathrm{ZnO}$ coatings. Comparative studies on the electrical and thermoelectric properties of un-doped and $\mathrm{Al}$ doped zinc oxide $(\mathrm{ZnO})$ thin coatings were performed. The $\mathrm{Al}$ doping was carried out using $25 \mathrm{keV}$ aluminum ion implantation. The doped concentration of aluminum into $\mathrm{ZnO}$ reached $0.1 \%, 1 \%$, and $2 \%$, respectively. From $X$-ray diffraction measurements, it is found that the lattice parameters of the doped coatings are larger than those of the values for bulk zinc oxide, indicating the incorporation of $\mathrm{Al}$ atoms at the interstitial sites. Al doping increased the electrical conductivity from $100(\mathrm{~S} / \mathrm{cm})$ for the un-doped $\mathrm{ZnO}$ coating to $598(\mathrm{~S} / \mathrm{cm})$ for the $2 \% \mathrm{Al}$ doped film. Electron doping by $\mathrm{Al}$ resulted in an increase in the carrier concentration. The mobility of charge career reached the highest for the $2 \% \mathrm{Al}-$ doped $\mathrm{ZnO}$. The absolute value of the Seebeck coefficient increased from $61 \mu \mathrm{V} / \mathrm{K}$ for the un-doped to $66 \mu \mathrm{V} / \mathrm{K}$ for the $2 \% \mathrm{Al}$-doped film. Consequently, the power factor increased significantly from $2.58 \times 10^{-5} \mathrm{~W} /\left(\mathrm{m} \cdot \mathrm{K}^{2}\right)$ for the un-doped $\mathrm{ZnO}$ to $2.63 \times 10^{-4} \mathrm{~W} /\left(\mathrm{m} \cdot \mathrm{K}^{2}\right)$ for the $2 \%$ Al doped coating.

Ion beam sputtering deposition was used by Zhang et al. [113] to prepare thermoelectric indium tin oxide (ITO) coating with the potential for thermal couple application from room temperature to $1200{ }^{\circ} \mathrm{C}$. The indium tin oxide (ITO) thin coating was directly deposited on an alumina substrate by ion beam sputtering from an ITO target with the composition of $\operatorname{In}_{2} \mathrm{O}_{3}: \mathrm{SnO}_{2}=1: 9$ in weight. The initial vacuum level in ion beam sputtering chamber was about $5 \times 10^{-4} \mathrm{~Pa}$. During the ion beam sputtering, the chamber pressure was sustained at $2 \times 10^{-2} \mathrm{~Pa}$. The energy level of the ion beam source was $0.9 \mathrm{keV}$. The electrical current of the ion source was $80 \mathrm{~mA}$. The obtained ITO coating showed an average Seebeck coefficient of $65.39 \mu \mathrm{V} / \mathrm{K}$. The thermal couple made by the ITO and Pt has stable thermoelectric outputs during both heating and cooling cycles.

Using the pulsed laser deposition (PLD) technique, Zhu et al. [114] prepared p-type $\mathrm{Ca}_{3} \mathrm{Co}_{4} \mathrm{O}_{9}(\mathrm{CCO})$ coatings on $c$-cut $\mathrm{Al}_{2} \mathrm{O}_{3}$ single crystal substrates via epitaxial growth. In addition, ion beam injection technique was used to inject different doses of $\mathrm{Nb}$ ions into the films. After that, annealing the specimens in pure nitrogen gas was conducted to allow a nanoscale $\mathrm{NbN}_{x}$ secondary phase formation in the films. To obtain the power factor of the coatings, the resistivity and Seebeck coefficient of the coatings were measured in the temperature range from 175 to $375 \mathrm{~K}$. The calculated power factor of the coatings was found to increase if appropriate amount of $\mathrm{Nb}$ was injected. When the injected $\mathrm{Nb}$ concentration was $1.46 \times 10^{20} / \mathrm{cm}^{3}$, the power factor of the coating, $0.17 \mathrm{~mW} /\left(\mathrm{m} \cdot \mathrm{K}^{2}\right)$, was twice as large as that of the pure $\mathrm{CCO}$ coating. The maximum power factor of the $\mathrm{Nb}$-ion injected coating reached $0.22 \mathrm{~mW} /\left(\mathrm{m} \cdot \mathrm{K}^{2}\right)$ at $375 \mathrm{~K}$.

Ion beam sputter deposition (IBSD) was also used to grow epitaxial oxide superlattice (SL) coatings consisting of Perovskite $\mathrm{SrTiO}_{3}$ (STO) and Nb-doped $\mathrm{SrTiO}_{3}$ (STNO) on $\mathrm{LaAlO}_{3}$ (LAO) (001) substrates [115]. The ion beam sputtering deposition (IBSD) system was installed with double electron cyclotron resonance (ECR) ion guns. The $\left[(\mathrm{STO})_{x} /(\mathrm{STNO})_{y}\right]_{10} \mathrm{SL}$ coatings grew epitaxially with the stacking sequences that $x=6 \mathrm{~nm}$, $y=1-6 \mathrm{~nm}$, and $z=10 . z$ is the maintained periodicity. It is found that the morphology, structure, and properties of the superlattice coatings are strongly dependent on the STNO sublayer thickness $(y)$. Highly strained SL coatings with two-dimensional growth mode are observed at smaller STNO sublayer thickness $(y=1 \mathrm{~nm})$. With the increase of thickness $y$ to a critical value of $4 \mathrm{~nm}$, the SL coatings are strain-free and transformed to the 
three-dimensional growth mode. It is concluded that the combined ECR-IBSD is a versatile technique for the growth of high-quality oxide SL coatings.

By combining pulsed laser deposition and electron beam lithography, it is possible to process complex oxide coatings with predefined patterns. Complex oxide coatings have many promising attributes, including wide band gaps for high temperature semiconductors, ion conducting electrolytes in fuel cells, ferroelectricity, and ferromagnetism. Both thin and thick oxide coatings can be readily manufactured by such a combined technology and tested. Typically, those physically hard and chemically inert materials can not be easily fabricated by direct application of conventional methods. In order to improve the thermoelectric properties of the oxide coatings at small scales, there must first be a simple and effective means to obtain the desired structures. As shown in [116], the use of pulsed laser deposition at room temperature onto electron beam lithography defined patterns of polymethyl methacrylate (PMMA) photoresist, and the $\mathrm{Nb}$-doped $\mathrm{SrTiO}_{3}$ coating was obtained. Following the photoresist liftoff procedure in organic solvents, a post heat treatment was carried out to crystallize the structure of the coating. The morphology of the coating was observed using both scanning electron microscopy and atomic force microscopy. Crystallinity and composition as determined by $\mathrm{X}$-ray diffraction and photoelectron spectroscopy were shown. In addition, the $\mathrm{Nb}$-doped $\mathrm{SrTiO}_{3}$ oxide coating obtained by this integrated technique has been investigated for high temperature thermoelectric energy conversion.

It is worth discussing a little bit more the electron beam technology especially for cases with reactive gases being introduced into the chamber for deposition. In Beke's review [117], electron beam deposition of vanadium pentoxide was described in more detail. The electron beam deposition was compared with the commonly used PVD processes for coating lenses and filters with anti-reflection, scratch-resistant, or other functional coatings. However, the e-beam method is not equivalent to the PVD processes such as resistive thermal evaporation in the sense that a high energy electron beam is the energy source for heating. The electron beam is electromagnetically focused on the target material. The kinetic energy of the electrons is converted into thermal energy as the electron beam bombards the target surface. Thus, the temperature increases, leading to the sublimation or formation of a liquid melt with a substantial vapor pressure. Some incident electron energy is lost in the excitation of X-rays and secondary electron emission. Electron beam deposition offers the possibility of precise control of deposition rate and coating composition, excellent material utilization, and sequential and co-deposition configurations. It also provides a low-energy atom flux with minimum contamination. Very high deposition rates can be achieved with precise structural and morphological control. Another advantage is the relatively low costs compared with pulsed laser deposition (PLD) and ion beam injection techniques. Electron beam deposition of $\mathrm{V}_{2} \mathrm{O}_{5}$ was demonstrated by Ramana et al. [118,119]. The properties of the vanadium oxide coating were found highly dependent on the oxygen partial pressure and deposition temperature. The reported optical band gaps varied from 2.04 to $2.66 \mathrm{eV}$ as a function of the oxygen partial pressure. The band gap values were found to be $2.50,2.66$, and $2.58 \mathrm{eV}$ for films deposited at the ambient temperature, and 300 and $400{ }^{\circ} \mathrm{C}$, respectively [120]. The coatings grown at the ambient temperature showed a homogeneous, uniform, and smooth texture, but are amorphous in nature. However, the coatings deposited at substrate temperatures higher than $200{ }^{\circ} \mathrm{C}$ illustrated the polycrystalline structure with the texture along $c$-axis. The color of the coatings changed from pale yellow to light brown, then to black corresponding to deposition at the ambient temperature, and 300 and $500{ }^{\circ} \mathrm{C}$, respectively. It was revealed that nanocrystalline $\mathrm{V}_{2} \mathrm{O}_{5}$ thin coatings with a [1] preferred orientation and a crystalline grain size of $17.7 \mathrm{~nm}$ grew on amorphous glass substrates at temperatures as low as $300^{\circ} \mathrm{C}$. Increasing the substrate temperature to $400{ }^{\circ} \mathrm{C}$ resulted in polycrystalline coatings with an average grain size of $11.4 \mathrm{~nm}[120]$. 


\section{Perspectives and Conclusions}

In summary, thermoelectric metallic oxide coatings are promising for high temperature thermoelectric energy conversion applications due to their high corrosion resistance. Several metallic oxide coatings with tuned structures are suitable for building energy converters and sensors due to their enhanced thermoelectric performances. These include the n-type $\mathrm{SrTiO}_{3}, \mathrm{LaAlO}_{3}, \mathrm{La}_{2} \mathrm{CuO}_{4}, \mathrm{TiO}_{2}$, and $\mathrm{ZnO}$, and the p-type $\mathrm{NaCo}_{2} \mathrm{O}_{4}, \mathrm{CuO} / \mathrm{Cu}_{2} \mathrm{O}$, and $\mathrm{Ca}_{3} \mathrm{Co}_{4} \mathrm{O}_{9}$. In view of the processing and manufacturing technology for thermoelectric oxide coating preparation, the liquid phase deposition, chemical vapor deposition, and plasma enhanced deposition are fast and cost-effective techniques. However, physical vapor deposition and high energy beam processing lead to more uniform coating formation. The high temperature method, chemical spray pyrolysis, allows selected compounds to be converted into oxides. There are still many challenges and new fields to explore for thermoelectric oxide coating processing. One of the challenges is to establish the processing and the thermoelectric performance relation. Since the figure of merit of most currently available oxide coatings is not so high, understanding the processing-property relation can guide the preparation of new oxide coatings with enhanced thermoelectric properties. Another issue is the lack of thermoelectric data of oxide coatings. More measurement studies will help develop thermoelectric property data bank of oxide coatings and understand the relationships among the composition, processing, structure, and property of oxide coatings. Comparative studies on the thermoelectric behavior of oxide coatings with oxides as embedded isolated phases in dissimilar materials [121] should be performed. It is also necessary to develop new measurement techniques for determining the thermal, electrical, and thermoelectric parameters of metal oxide coatings with high precision.

Funding: This research received no external funding.

Institutional Review Board Statement: Not applicable.

Informed Consent Statement: Not applicable.

Conflicts of Interest: The author declares no conflict of interest.

\section{References}

1. Klochko, N.P.; Klepikova, K.S.; Khrypunova, I.V.; Zhadan, D.O.; Petrushenko, S.I.; Kopach, V.R.; Dukarov, S.V.; Sukhov, V.M.; Kirichenko, M.V.; Khrypunova, A.L. Flexible thermoelectric module based on zinc oxide thin film grown via SILAR. Curr. Appl. Phys. 2021, 21, 121-133. [CrossRef]

2. Kumar, A.; Sivaprahasam, D.; Thakur, A.D. Colossal Seebeck coefficient in Aurivillius phase-perovskite oxide composite. J. Alloys Compd. 2021, 853, 157001. [CrossRef]

3. Zhu, L.; Chen, L.X.; Li, H.Q.; Li, D.; Yang, N.; Jiang, X.B.; Qiu, S.Z. Performance analysis of alkali metal thermoelectric converter and segmented thermoelectric generator hybrid system based on a comprehensive model. Appl. Thermal. Eng. 2021, $183,116206$. [CrossRef]

4. Tian, X.X.; Asaadi, S.; Moria, H.; Kaood, A.; Pourhedayat, S.; Jermsittiparsert, K. Proposing tube-bundle arrangement of tubular thermoelectric module as a novel air cooler. Energy 2020, 208, 118428. [CrossRef]

5. Gan, Y.X. Nanomaterials for Thermoelectric Devices, 1st ed.; Jenny Stanford Publishing: Singapore, 2018; pp. 6-8.

6. Boulat, L.; Viennois, R.; Oliviero, E.; Dadras, M.; Fréty, N. Study of TaN and TaN-Ta-TaN thin films as diffusion barriers in $\mathrm{CeFe}_{4} \mathrm{Sb}_{12}$ skutterudite. J. Appl. Phys. 2019, 126, 125306. [CrossRef]

7. Appel, O.; Zaharoni, T.; Breuer, G.; Beeri, O.; Gelbstein, Y. Thermoelectric properties of $\mathrm{Ti}_{0.3} \mathrm{Zr}_{0.35} \mathrm{Hf}_{0.35} \mathrm{Ni}_{1.005} \mathrm{Sn} \mathrm{Half} \mathrm{Heusler}$ alloy. J. Appl. Phys. 2019, 126, 085110. [CrossRef]

8. Zeier, W.G.; Schmitt, J.; Hautier, G.; Aydemir, U.; Gibbs, Z.M.; Felser, C.; Snyder, G.J. Engineering Half-Heusler thermoelectric materials using Zintl chemistry. Nat. Rev. Mater. 2016, 1, 16032. [CrossRef]

9. Landmann, D.; Tang, Y.; Kunz, B.; Huber, R.; Widner, D.; Rickhaus, P.; Widmer, R.N.; Elsener, H.R.; Battaglia, C. Fabrication, characterization, and application-matched design of thermoelectric modules based on Half-Heusler FeNbSb and TiNiSn. J. Appl. Phys. 2019, 126, 085113. [CrossRef]

10. Rogl, G.; Ghosh, S.; Wang, L.; Bursik, J.; Grytsiv, A.; Kerber, M.; Bauer, E.; Mallik, R.C.; Chen, X.Q.; Zehetbauer, M.; et al. Half-Heusler alloys: Enhancement of ZT after severe plastic deformation (ultra-low thermal conductivity). Acta Mater. 2020, 183, 285-300. [CrossRef]

11. Gürth, M.; Rogl, G.; Romaka, V.V.; Grytsiv, A.; Bauer, E.; Rogl, P. Thermoelectric high ZT Half-Heusler alloys $\mathrm{Ti}_{1-x-y} \mathrm{Zr}_{x} \mathrm{Hf}_{y} \mathrm{NiSn}_{\text {. }}$ Acta Mater. 2016, 104, 210-222. [CrossRef] 
12. Tavassoli, A.; Failamani, F.; Grytsiv, A.; Rogl, G.; Heinrich, P.; Müller, H.; Bauer, E.; Zehetbauer, M.; Rogl, P. On the Half-Heusler compounds $\mathrm{Nb}_{1-x}\{\mathrm{Ti}, \mathrm{Zr}, \mathrm{Hf}\}_{x} \mathrm{FeSb}$ : Phase relations, thermoelectric properties at low and high temperature, and mechanical properties. Acta Mater. 2017, 135, 263-276. [CrossRef]

13. Shi, Y.; Sturm, C.; Kleinke, H. Chalcogenides as thermoelectric materials. J. Solid State Chem. 2019, 270, 273-279. [CrossRef]

14. Gelbstein, Y.; Dashevsky, Z.; Dariel, M.P. High performance n-type PbTe-based materials for thermoelectric applications. Phys. B 2005, 363, 196-205. [CrossRef]

15. Guo, Q.; Assoud, A.; Kleinke, H. Improved bulk materials with thermoelectric figure-of-merit $>1: \mathrm{Tl}_{10-x} \mathrm{Sn}_{x} \mathrm{Te}_{6} \mathrm{and}_{10-x} \mathrm{~Pb}_{x} \mathrm{Te}_{6}$. Adv. Energy Mater. 2014, 4, 1400348. [CrossRef]

16. Zhao, L.D.; Chang, C.; Tan, G.; Kanatzidis, M.G. SnSe: A remarkable new thermoelectric material. Energy Environ. Sci. 2016, 9 , 3044-3060. [CrossRef]

17. Zhao, L.D.; Lo, S.H.; Zhang, Y.S.; Sun, H.; Tan, G.H.; Uher, C.; Wolverton, C.; Dravid, V.P.; Kanatzidis, M.G. Ultralow thermal conductivity and high thermoelectric figure of merit in SnSe crystals. Nature 2014, 508, 373-377. [CrossRef]

18. Liu, H.; Shi, X.; Xu, F.; Zhang, L.; Zhang, W.; Chen, L.; Li, Q.; Uher, C.; Day, T.; Snyder, G.J. Copper ion liquid-like thermoelectrics. Nat. Mater. 2021, 11, 422-425. [CrossRef] [PubMed]

19. Assoud, A.; Thomas, S.; Sutherland, B.; Zhang, H.; Tritt, T.M.; Kleinke, H. Thermoelectric properties of the new polytelluride $\mathrm{Ba}_{3} \mathrm{Cu}_{14-\delta} \mathrm{Te}_{12}$. Chem. Mater. 2006, 18, 3866-3872. [CrossRef]

20. Shi, Y.X.; Assoud, A.; Sankar, C.R.; Kleinke, H. TlAg ${ }_{12} \mathrm{Se}_{7}$ : A new pnp conduction switching material with extraordinarily low thermal conductivity. Chem. Mater. 2017, 29, 9565-9571. [CrossRef]

21. Snedaker, M.L.; Zhang, Y.; Birkel, C.S.; Wang, H.; Day, T.; Shi, Y.; Ji, X.; Kraemer, S.; Mills, C.E.; Moosazadeh, A.; et al. Silicon-based thermoelectrics made from a boron-doped silicon dioxide nanocomposite. Chem. Mater. 2013, 25, 4867-4873. [CrossRef]

22. Zhou, Y.; Hu, M. Record low thermal conductivity of polycrystalline Si nanowire: Breaking the Casimir limit by severe suppression of propagons. Nano Lett. 2016, 16, 6178-6187. [CrossRef] [PubMed]

23. Ferrer-Argemi, L.; Yu, Z.; Lee, J. Effects of metal silicide inclusion interface and shape on thermal transport in silicon nanocomposites. J. Appl. Phys. 2019, 126, 035106. [CrossRef]

24. Nakasawa, H.; Hayashi, K.; Takamatsu, T.; Miyazaki, Y. Lattice dynamics and lattice thermal conductivity of $\mathrm{CrSi}_{2}$ calculated from first principles and the phonon Boltzmann transport equation. J. Appl. Phys. 2019, 126, 025105. [CrossRef]

25. Murphy-Armando, F. Enhancement of the electronic thermoelectric properties of bulk strained silicon-germanium alloys using the scattering relaxation times from first principles calculations. J. Appl. Phys. 2019, 126, 215103. [CrossRef]

26. Antonov, A.; Ivanov, Y.; Konstantinov, P.; Kuznetsova, V.; Novikov, S.; Ovchinnikov, A.; Pshenay-Severin, D.; Burkov, A. Thermoelectric and galvanomagnetic properties of topologically non-trivial (Co-M)Si semimetals $(M=\mathrm{Fe}, \mathrm{Ni})$ at high temperatures. $J$. Appl. Phys. 2019, 126, 245103. [CrossRef]

27. Khalil, M.; Moll, A.; Godfroy, M.; Letrouit-Lebranchu, A.; Villeroy, B.; Alleno, E.; Viennois, R.; Beaudhuin, M. Thermoelectric properties and stability of nanostructured chromium disilicide $\mathrm{CrSi}_{2}$. J. Appl. Phys. 2019, 126, 135103. [CrossRef]

28. Nonoguchi, Y.; Tani, A.; Kitano, T.; Kawai, T. Enhanced thermoelectric properties of semiconducting carbon nanotube films by UV/ozone treatment. J. Appl. Phys. 2019, 126, 135108. [CrossRef]

29. Kim, G.; Kim, S.W.; Rim, H.J.; Lee, H.; Kim, J.; Roh, J.W.; Kim, B.W.; Lee, K.H.; Lee, W. Improved trade-off between thermoelectric performance and mechanical reliability of $\mathrm{Mg}_{2} \mathrm{Si}$ by hybridization of few-layered reduced graphene oxides. Script. Mater. 2019, 162, 402-407. [CrossRef]

30. Tan, X.; Liu, Y.C.; Liu, R.; Zhou, Z.F.; Liu, C.; Lan, J.L.; Zhang, Q.H.; Lin, Y.H.; Nan, C.W. Synergistical enhancement of thermoelectric properties in n-type $\mathrm{Bi}_{2} \mathrm{O}_{2}$ Se by carrier engineering and hierarchical microstructure. Adv. Energy Mater. 2019, 9, 1900354. [CrossRef]

31. Kenfaui, D.; Lenoir, B.; Chateigner, D.; Ouladdiaf, B.; Gomina, M.; Noudem, J.G. Development of multilayer textured $\mathrm{Ca}_{3} \mathrm{Co}_{4} \mathrm{O}_{9}$ materials for thermoelectric generators: Influence of the anisotropy on the transport properties. J. Eur. Ceram. Soc. 2012, 32, 2405-2414. [CrossRef]

32. Yin, Y.; Tudu, B.; Tiwari, A. Recent advances in oxide thermoelectric materials and modules. Vacuum 2017, 146, 356-374. [CrossRef]

33. Baranovskiy, A.; Amouyal, Y. Structural stability of calcium-manganate based $\mathrm{CaO}\left(\mathrm{CaMnO}_{3}\right)_{m}(m=1,2,3, \infty)$ compounds for thermoelectric applications. J. Alloys Compd. 2016, 687, 562-569. [CrossRef]

34. Tauc, J. The thermal photo-electric phenomenon in semi-conductors. Cechoslov. Fiz. Zurnal (Czechoslov. J. Phys.) 1955, 5, 528-535. [CrossRef]

35. Kwok, H.B.; Bube, R.H. Thermoelectric and photothermoelectric effects in semiconductors: CdS single crystals. J. Appl. Phys. 1973, 44, 138. [CrossRef]

36. Harper, J.G.; Matthews, H.E.; Bube, R.H. Photothermoelectric Effects in semiconductors: N- and p-type silicon. J. Appl. Phys. 1970, 41, 765. [CrossRef]

37. Shiraishi, Y.; Tanabe, K.; Taniguchi, H.; Okazaki, R.; Terasaki, I. Interplay between quantum paraelectricity and thermoelectricity in the photo-Seebeck effect in a single crystal. J. Appl. Phys. 2019, 126, 045111. [CrossRef]

38. Okazaki, R.; Horikawa, A.; Yasui, Y.; Terasaki, I. Photo-Seebeck effect in ZnO. J. Phys. Soc. Jpn. 2012, 81, 114722. [CrossRef]

39. Horikawa, A.; Igarashi, T.; Terasaki, I.; Okazaki, R. Photo-Seebeck effect in polycrystalline ZnO. J. Appl. Phys. 2015, 118, 095101. [CrossRef]

40. Tanabe, K. Influence of carrier diffusion on photo-Seebeck effect in zinc oxide. J. Appl. Phys. 2018, 124, 035108. [CrossRef] 
41. Suzuki, K.; Watanabe, T.; Kakemoto, H.; Irie, H. Photo- and gas-tuned, reversible thermoelectric properties and anomalous photo-thermoelectric effects of platinum-loaded tungsten trioxide. J. Appl. Phys. 2016, 119, 245109. [CrossRef]

42. Azuma, C.; Kawano, T.; Kakemoto, H.; Irie, H. Photo-controllable thermoelectric properties with reversibility and photothermoelectric effects of tungsten trioxide accompanied by its photochromic phenomenon. J. Appl. Phys. 2014, 116, 173502. [CrossRef]

43. Mondal, P.S.; Okazaki, R.; Taniguchi, H.; Terasaki, I. Photo-Seebeck effect in tetragonal PbO single crystals. J. Appl. Phys. 2013, 114, 173710. [CrossRef]

44. Diez, J.C.; Torres, M.A.; Rasekh, S.; Constantinescu, G.; Madre, M.A.; Sotelo, A. Enhancement of $\mathrm{Ca}_{3} \mathrm{Co}_{4} \mathrm{O}_{9}$ thermoelectric properties by $\mathrm{Cr}$ for Co substitution. Ceram. Int. 2013, 39, 6051-6056. [CrossRef]

45. Liu, J.; Wang, J.; Wang, C.; Xia, S. Ce ${ }_{1-x} \mathrm{Sr}_{x} \mathrm{ZnSbO}$ : New thermoelectric materials formed between intermetallics and oxides. J. Alloys Compd. 2016, 688, 849-853. [CrossRef]

46. Zhang, Y.; Sugo, K.; Cho, H.J.; Ohta, H. Thermoelectric phase diagram of the $\mathrm{SrTiO}_{3}-\mathrm{LaTiO}_{3}$ solid-solution system through a metal to Mott insulator transition. J. Appl. Phys. 2019, 126, 075104. [CrossRef]

47. Bresch, S.; Mieller, B.; Schoenauer-Kamin, D.; Moos, R.; Giovanelli, F.; Rabe, T. Influence of pressure assisted sintering and reaction sintering on microstructure and thermoelectric properties of bi-doped and undoped calcium cobaltite. J. Appl. Phys. 2019, 126, 075102. [CrossRef]

48. Jerič, M.; de Boor, J.; Jančar, B.; Ceh, M. An enhanced thermoelectric figure of merit for $\operatorname{Sr}\left(\operatorname{Ti}_{0.8} \mathrm{Nb}_{0.2}\right) \mathrm{O}_{3}$ based on a RuddlesdenPopper-polytype-induced microstructure. J. Eur. Ceram. Soc. 2016, 36, 1177-1182. [CrossRef]

49. Han, J.; Sun, Q.; Li, W.; Song, Y. Microstructure and thermoelectric properties of $\mathrm{La}_{0.1} \mathrm{Dy}_{0.1} \mathrm{Sr}_{x} \mathrm{TiO}_{3}$ ceramics. Ceram. Int. 2017, 43, 5557-5563. [CrossRef]

50. Tiginyanu, I.M.; Lupan, O.; Ursaki, V.V.; Chow, L.; Enachi, M. Nanostructures of metal oxides. In Comprehensive Semiconductor Science and Technology; Bhattacharya, P., Fornari, R., Kamimura, H., Eds.; Elsevier B.V.: Amsterdam, The Netherlands, 2011; Volume 3, pp. 396-479.

51. Matsuo, J.; Katsumata, H.; Minami, E.; Yamada, I. $\mathrm{O}_{2}$ cluster ion-assisted deposition for tin-doped indium oxide films. Nucl. Instrum. Methods Phys. Res. Sec. B Beam Interact. Mater. At. 2000, 161-163, 952-957. [CrossRef]

52. Therese, G.H.A.; Kamath, P.V. Electrochemical synthesis of metal oxides and hydroxides. Chem. Mater. 2000, 12, 1195-1204. [CrossRef]

53. Esposito, S. "Traditional" sol-gel chemistry as a powerful tool for the preparation of supported metal and metal oxide catalysts. Materials 2019, 12, 668. [CrossRef] [PubMed]

54. Zhang, H.; Ning, H.; Busbee, J.; Shen, Z.; Kiggins, C.; Hua, Y.; Eaves, J.; Davis III, J.; Shi, T.; Shao, Y.T.; et al. Electroplating lithium transition metal oxides. Sci. Adv. 2017, 3, e1602427. [CrossRef] [PubMed]

55. Liu, Z.; Guo, R.; Meng, J.; Liu, X.; Wang, X.; Li, Q.; Mai, L. Facile electrospinning formation of carbon-confined metal oxide cube-in-tube nanostructures for stable lithium storage. Chem. Commun. 2017, 53, 8284-8287. [CrossRef] [PubMed]

56. Tsukuma, K.; Akiyama, T.; Imai, H. Liquid phase deposition film of tin oxide. J. Non Cryst. Solids 1997, 210, 48-54. [CrossRef]

57. Deng, X.; Chen, K.; Tüysüz, H. Protocol for the nanocasting method: Preparation of ordered mesoporous metal oxides. Chem. Mater. 2017, 29, 40-52. [CrossRef]

58. Ozegowski, M.; Meteva, K.; Metev, S.; Sepold, G. Pulsed laser deposition of multicomponent metal and oxide films. Appl. Surf. Sci. 1999, 138-139, 68-74. [CrossRef]

59. Kathalingam, A.; Shanmugam, K.; Park, H.C.; Kim, H.S. Fabrication of arrayed metal oxide structures by electrochemical local oxidation using metallic tip with electric field and humidity. J. Mater. Proc. Technol. 2018, 252, 304-312. [CrossRef]

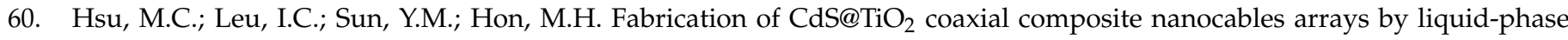
deposition. J. Cryst. Growth 2005, 285, 642-648. [CrossRef]

61. Wu, J.M.; Wu, W.T.; Shih, H.C. Characterization of single-crystalline $\mathrm{TiO}_{2}$ nanowires grown by thermal evaporation. J. Electrochem. Soc. 2005, 152, G613. [CrossRef]

62. Wang, Z.L. Functional oxide nanobelts: Materials, properties and potential applications in nanosystems and biotechnology. Annu. Rev. Phys. Chem. 2004, 55, 159-196. [CrossRef]

63. Zhao, S.; Wang, L.; Yang, L.; Chen, Y. Synthesis and ultraviolet luminescence properties of half-wall $\mathrm{Al}_{2} \mathrm{O}_{3}$ nanotube arrays. J. Phys. D Appl. Phys. 2009, 42, 225106. [CrossRef]

64. Li, P.G.; Lei, M.; Tang, W.H.; Guo, X.; Wang, X. Facile route to straight $\mathrm{SnO}_{2}$ nanowires and their optical properties. J. Alloys Compd. 2009, 477, 515-518. [CrossRef]

65. Jiang, X.; Herricks, T.; Xia, Y. CuO nanowires can be synthesized by heating copper substrates in air. Nano Lett. 2002, 2, $1333-1338$. [CrossRef]

66. Xiang, X.; Cao, C.B.; Guo, Y.; Zhu, H.S. A simple method to synthesize gallium oxide nanosheets and nanobelts. Chem. Phys. Lett. 2003, 378, 660. [CrossRef]

67. Cha, H.G.; Kim, C.W.; Kim, Y.H.; Jung, M.H.; Ji, E.S.; Das, B.K.; Kim, J.C.; Kang, Y.S. Preparation and characterization of $\alpha$-Fe ${ }_{2} \mathrm{O}_{3}$ nanorod-thin film by metal-organic chemical vapor deposition. Thin Solid Film. 2009, 517, 1853-1856. [CrossRef]

68. Basharat, S.; Carmalt, C.J.; Barnett, S.A.; Tocher, D.A.; Davies, H.O. Aerosol assisted chemical vapor deposition of $\mathrm{In}_{2} \mathrm{O}_{3}$ films from $\mathrm{Me}_{3}$ In and donor functionalized alcohols. Inorg. Chem. 2007, 46, 9473-9480. [CrossRef] 
69. Terasako, T.; Ohmae, K.; Yamane, M.; Shirakata, S. Carrier transport in undoped CdO films grown by atmospheric-pressure chemical vapor deposition. Thin Solid Film. 2014, 572, 20-27. [CrossRef]

70. Stetsovych, V.; Pagliuca, F.; Dvořák, F.; Duchoň, T.; Vorokhta, M.; Aulická, M.; Lachnitt, J.; Schernich, S.; Matolínová, I.; Veltruská, K.; et al. Epitaxial cubic $\mathrm{Ce}_{2} \mathrm{O}_{3}$ films via $\mathrm{Ce}-\mathrm{CeO}_{2}$ interfacial reaction. J. Phys. Chem. Lett. 2013, 4, 866-871. [CrossRef]

71. Ahmoum, H.; Li, G.J.; Belakry, S.; Boughrara, M.; Suait, M.S.; Kerouad, M.; Wang, Q. Structural, morphological and transport properties of $\mathrm{Ni}$ doped $\mathrm{ZnO}$ thin films deposited by thermal co-evaporation method. Mater. Sci. Semicond. Proc. 2021, 123, 105530. [CrossRef]

72. Baptista, A.; Silva, F.; Porteiro, J.; Míguez, J.; Pinto, G. Sputtering physical vapour deposition (PVD) coatings: A critical review on process improvement and market trend demands. Coatings 2018, 8, 402. [CrossRef]

73. Perednis, D.; Gauckler, L.J. Thin film deposition using spray pyrolysis. J. Electroceram. 2005, 14, 103-111. [CrossRef]

74. Arca, E.; Fleischer, K.; Shvets, I.V. Influence of the precursors and chemical composition of the solution on the properties of ZnO thin films grown by spray pyrolysis. J. Phys. Chem. C 2009, 113, 21074-21081. [CrossRef]

75. Hateef, A.A. Effect of the thickness on electrical properties of $\mathrm{TiO}_{2}$ thin films, prepared by thermal chemical spray pyrolysis deposition. Int. J. Innov. Res. Sci. Eng. Technol. (Irjesti) 2012, 1, 175-179.

76. Andronic, L.; Manolache, S.; Duta, $\mathrm{A}$. $\mathrm{TiO}_{2}$ thin films prepared by spray pyrolysis deposition (SPD) and their photocatalytic activities. J. Optoelectron. Adv. Mater. 2007, 9, 1403-1406.

77. Boyadzhiev, S.; Georgieva, V.; Rassovska, M. Characterization of reactive sputtered $\mathrm{TiO}_{2}$ thin films for gas sensor applications. J. Phys. Conf. Ser. 2010, 253, 012040. [CrossRef]

78. Hussian, H.A.R.A.; Hassan, M.A.M.; Agool, I.R. Synthesis of titanium dioxide $\left(\mathrm{TiO}_{2}\right)$ nanofiber and nanotube using different chemical method. Optik 2016, 127, 2996-2999. [CrossRef]

79. Ennaceri, H.; Boujnah, M.; Taleb, A.; Khaldoun, A.; Sáez-Araoz, R.; Ennaoui, A.; Kenz, A.E.; Benyoussef, A. Thickness effect on the optical properties of $\mathrm{TiO}_{2}$-anatase thin films prepared by ultrasonic spray pyrolysis: Experimental and ab initio study. Int. J. Hydrog. Energy 2017, 42, 19467-19480. [CrossRef]

80. Oja, I.; Mere, A.; Krunks, M.; Solterbeck, C.H.; Es-Souni, M. Properties of $\mathrm{TiO}_{2}$ films prepared by the spray pyrolysis method. In Functional Nanomaterials for Optoelectronics and Other Applications; Lojkowski, W., Blizzard, J.R., Eds.; Solid State Phenom; Trans Tech Publications Ltd.: Stafa-Zurich, Switzerland, 2004; Volume 99-100, pp. 259-264. [CrossRef]

81. Castaneda, L.; Alonso, J.C.; Ortiz, A.; Andrade, E.; Saniger, J.M.; Banuelos, J.G. Spray pyrolysis deposition and characterization of titanium oxide thin films. Mater. Chem. Phys. 2003, 77, 938-944. [CrossRef]

82. Vautey, C.; Burgos, M.; Langlet, M. Aerosol-gel deposition and low temperature heat-treatment of $\mathrm{SiO}_{2}$ layers. Thin Solid Film. 1999, 347, 184-194. [CrossRef]

83. Djaoued, Y.; Taj, R.; Brüning, R.; Badilescu, S.; Ashrit, P.V.; Bader, G.; Vo-Van, T. Study of the phase transition and the thermal nitridation of nanocrystalline sol-gel titania films. J. Non Cryst. Solids 2002, 297, 55-66. [CrossRef]

84. Burgos, M.; Langlet, M. The sol-gel transformation of TIPT coatings: A FTIR study. Thin Solid Film. 1999, 349, 19-23. [CrossRef]

85. Alam, M.J.; Cameron, D.C. Preparation and characterization of $\mathrm{TiO}_{2}$ thin films by sol-gel method. J. Sol Gel Sci. Technol. 2002, 25, 137-145. [CrossRef]

86. Yao, T.; Uchimoto, Y.; Sugiyama, T.; Nagai, Y. Synthesis of ( $\mathrm{La}, \mathrm{Sr}) \mathrm{MeO}_{3}(\mathrm{Me}=\mathrm{Cr}, \mathrm{Mn}, \mathrm{Fe}, \mathrm{Co})$ solid solutions from aqueous solutions. Solid State Ion. 2000, 135, 359-364. [CrossRef]

87. Deki, S.; Iizuka, S.; Akamatsu, K.; Mizuhata, M.; Kajinami, A. Novel fabrication method for $\mathrm{Si}_{1-x} \mathrm{Ti}_{x} \mathrm{O}_{2}$ thin films with graded composition profiles by liquid phase deposition. J. Mater. Chem. 2001, 11, 984-986. [CrossRef]

88. Koumoto, K.; Seo, S.; Sugiyama, T.; Seo, W.S.; Dressick, W.J. Micropatterning of titanium dioxide on self-assembled monolayers using a liquid-phase deposition process. Chem. Mater. 1999, 11, 2305-2309. [CrossRef]

89. Deki, S.; Aoi, Y.; Asaoka, Y.; Kajinami, A.; Mizuhata, M. Preparation and characterization of Au-dispersed TiO 2 thin films by a liquid-phase deposition method. J. Mater. Chem. 1996, 7, 733-736. [CrossRef]

90. Gao, Y.; Masuda, Y.; Yonezawa, T.; Koumoto, K. Preparation of $\mathrm{SrTiO}_{3}$ thin films by the liquid phase deposition method. Mater. Sci. Eng. B 2003, 99, 290-293. [CrossRef]

91. Su, L.; Gan, Y.X.; Zhang, L. Thermoelectricity of nanocomposites containing $\mathrm{TiO}_{2}-\mathrm{CoO}$ coaxial nanocables. Script. Mater. 2011, 64, 745-748. [CrossRef]

92. Chen, L.L.; Zhang, Z.Y.; Qi, N.; Zhou, B.; Deng, S.P.; Chen, Z.Q.; Wu, Y.C.; Tang, X.F. Giant reduction in thermal conductivity of $\mathrm{Co}_{3} \mathrm{O}_{4}$ with ordered mesopore structures. Microporous Mesoporous Mater. 2020, 296, 109969. [CrossRef]

93. Zhou, B.; Li, C.Y.; Qi, N.; Jiang, M.; Wang, B.; Chen, Z.Q. Pore structure of mesoporous silica (KIT-6) synthesized at different temperatures using positron as a nondestructive probe. Appl. Surf. Sci. 2018, 450, 31-37. [CrossRef]

94. Sun, S.; Gao, Q.; Wang, H.; Zhu, J.; Guo, H. Influence of textural parameters on the catalytic behavior for CO oxidation over ordered mesoporous $\mathrm{Co}_{3} \mathrm{O}_{4}$. Appl. Catal. B Environ. 2010, 97, 284-291. [CrossRef]

95. Jiang, D.; Ekren, D.; Azough, F.; Day, S.J.; Chen, K.; Mahajan, A.; Kepaptsoglou, D.M.; Ramasse, Q.M.; Reece, M.J.; Freer, R. The structure and thermoelectric properties of tungsten bronze $\mathrm{Ba}_{6} \mathrm{Ti}_{2} \mathrm{Nb}_{8} \mathrm{O}_{30}$. J. Appl. Phys. 2019, 126, 125115. [CrossRef]

96. Presečnik, M.; Bernik, S. Microstructural and thermoelectric properties of $\mathrm{WO}_{3}$-doped $\mathrm{Ca}_{3} \mathrm{Co}_{4} \mathrm{O}_{9}$ ceramics. Ceram. Int. 2016, 42, 16103-16108. [CrossRef]

97. Kahraman, F.; Madre, M.A.; Rasekh, S.; Salvador, C.; Bosque, P.; Torres, M.A.; Diez, J.C.; Sotelo, A. Enhancement of mechanical and thermoelectric properties of $\mathrm{Ca}_{3} \mathrm{Co}_{4} \mathrm{O}_{9}$ by Ag addition. J. Eur. Ceram. Soc. 2015, 35, 3835-3841. [CrossRef] 
98. Demirel, S.; Altin, E.; Oz, E.; Altin, S.; Bayri, A. An enhancement ZT and spin state transition of $\mathrm{Ca}_{3} \mathrm{Co}_{4} \mathrm{O}_{9}$ with Pb doping. J. Alloys Compd. 2015, 627, 430-437. [CrossRef]

99. Yu, J.; Li, T.; Sun, Q. Single-layer BiOBr: An effective p-type 2D thermoelectric material. J. Appl. Phys. 2019, 125, 205111. [CrossRef]

100. Pöhls, J.H.; Mar, A. Thermoelectric properties of inverse perovskites $A_{3} \mathrm{TtO}(A=\mathrm{Mg}$, Ca; $\mathrm{Tt}=\mathrm{Si}$, Ge $)$ : Computational and experimental investigations. J. Appl. Phys. 2019, 126, 025110. [CrossRef]

101. Madre, M.A.; Rasekh, S.; Diez, J.C.; Sotelo, A. New solution method to produce high performance thermoelectric ceramics: A case study of Bi-Sr-Co-O. Mater. Lett. 2010, 64, 2566-2568. [CrossRef]

102. Sotelo, A.; Rasekh, S.; Madre, M.A.; Guilmeau, E.; Marinel, S.; Diez, J.C. Solution-based synthesis routes to thermoelectric $\mathrm{Bi}_{2} \mathrm{Ca}_{2} \mathrm{Co}_{1.7} \mathrm{O}_{x}$. J. Eur. Ceram. Soc. 2011, 31, 1763-1769. [CrossRef]

103. Griesser, A.; Kraus, T.; Klein, O.; Karl, H. Low-resistance electrical contact between epitaxially grown thermoelectric oxide material $\left(\mathrm{Ca}_{2} \mathrm{CoO}_{3}\right)(0.62) \mathrm{CoO}_{2}$ and iridium. Thin Solid Film. 2021, 717, 138420. [CrossRef]

104. Jones, J.G.; Boeckl, J.J.; Smith, S.R.; Landis, G.R.; Murphy, N.R.; Hu, Z.Q.; Bowers, C.T.; Stutz, C.E. $\mathrm{Al}_{2} \mathrm{O}_{3}-\mathrm{BaTiO}_{3}$ nanolaminates fabricated by multistationary target pulsed laser deposition with in situ ellipsometry. J. Nanophotonics 2017, 11, 043506. [CrossRef]

105. Gutierrez-Llorente, A.; Iglesias, L.; Rodriguez-Gonzalez, B.; Rivadulla, F. Epitaxial stabilization of pulsed laser deposited $\mathrm{Sr}_{n+1} \mathrm{Ir}_{n} \mathrm{O}_{3 n+1}$ thin films: Entangled effect of growth dynamics and strain. APL Mater. 2018, 6, 091101. [CrossRef]

106. Kulik, P.; Yu, C.J.; Sokolov, A.; Liang, W.T.; Harris, V.G. $\mathrm{BaFe}_{12} \mathrm{O}_{19}$ magnetoplumbite films grown on $\mathrm{SiO}_{2} / \mathrm{Si}$ substrates for widescale magnetic film semiconductor systems integration. Scr. Mater. 2020, 188, 190-194. [CrossRef]

107. Xiao, T.T.; Yang, Q.; Yu, J.; Xiong, Z.W.; Wu, W.D. Annealing condition effects on the structural properties of FePt nanoparticles embedded in $\mathrm{MgO}$ via pulsed laser deposition. Nanomaterials 2021, 11, 131. [CrossRef] [PubMed]

108. Cesaria, M.; Lorusso, A.; Caricato, A.P.; Finocchiaro, P.; Amaducci, S.; Martino, M.; Aziz, M.R.; Calcagnile, L.; Perrone, A.; Quarta, G. B-10-based films grown by pulsed laser deposition for neutron conversion applications. Appl. Phys. A Mater. Sci. Proc. 2020, 126, 404. [CrossRef]

109. Bhogra, A.; Masarrat, A.; Meena, R.; Hasina, D.; Bala, M.; Dong, C.L.; Chen, C.L.; Kumar, T.A.; Kandasami, A. Tuning the electrical and thermoelectric properties of $\mathrm{N}$ ion implanted $\mathrm{SrTiO}_{3}$ thin films and their conduction mechanisms. Sci. Rep. 2019, 9, 14486. [CrossRef] [PubMed]

110. Bhogra, A.; Masarrat, A.; Hasina, D.; Meena, R.; Umapathy, G.R.; Kumar, A.; Som, T.; Dong, C.L.; Chen, C.L.; Kandasami, A. Significant role of substrate temperature on the morphology, electronic structure and thermoelectric properties of $\mathrm{SrTiO}_{3}$ films deposited by pulsed laser deposition. Surf. Coat. Technol. 2021, 407, 126740. [CrossRef]

111. Christopher, B.; Rao, A.; Deka, U.; Prasad, K.S.; Okram, G.S.; Sanjeev, G.; Petwal, V.C.; Verma, V.P.; Dwivedi, J. Electrical, thermal and magnetic studies on $7.5 \mathrm{MeV}$ electron beam irradiated $\mathrm{PrCoO}_{3}$ polycrystalline samples. Phys. B Condens. Matter 2018, 540, 26-32. [CrossRef]

112. Kennedy, J.; Murmu, P.P.; Leveneur, J.; Williams, G.V.W.; Moody, R.L.; Maity, T.; Chong, S.V. Enhanced power factor and increased conductivity of aluminum doped zinc oxide thin films for thermoelectric applications. J. Nanosci. Nanotechnol. 2018, 18, $1384-1387$. [CrossRef]

113. Zhang, Y.; Cheng, P.; Yu, K.Q.; Zhao, X.L.; Ding, G.F. ITO film prepared by ion beam sputtering and its application in hightemperature thermocouple. Vacuum 2017, 146, 31-34. [CrossRef]

114. Zhu, C.H.; Li, Z.Z.; An, H.P.; Tang, G.D.; Hou, D.L. Enhancing the thermoelectric properties of $\mathrm{Ca}_{3} \mathrm{Co}_{4} \mathrm{O}_{9}$ thin films by the addition of a nanoscale $\mathrm{NbN}_{x}$ second phase. J. Electron. Mater. 2014, 43, 3666-3671. [CrossRef]

115. Panomsuwan, G.; Takai, O.; Saito, N. Fabrication and characterization of epitaxial $\mathrm{SrTiO}_{3} / \mathrm{Nb}$-doped $\mathrm{SrTiO}_{3}$ superlattices by double ECR ion beam sputter deposition. Vacuum 2013, 89, 35-39. [CrossRef]

116. Waller, G.; Stein, A.; Abiade, J.T. Nanofabrication of doped, complex oxides. J. Vac. Sci. Technol. B 2012, 30, 011804. [CrossRef]

117. Beke, S. A review of the growth of $\mathrm{V}_{2} \mathrm{O}_{5}$ films from 1885 to 2010. Thin Solid Film 2011, 519, 1761-1771. [CrossRef]

118. Ramana, C.V.; Hussain, O.M.; Naidu, B.S.; Reddy, P.J. Influence of substrate temperature on the composition and structural properties of electron beam evaporated $\mathrm{V}_{2} \mathrm{O}_{5}$ thin films. Vacuum 1997, 48, 431-434. [CrossRef]

119. Ramana, C.V.; Hussain, O.M.; Uthanna, S.; Naidu, B.S. Influence of oxygen partial pressure on the optical properties of electron beam evaporated vanadium pentoxide thin films. Opt. Mater. 1998, 10, 101-107. [CrossRef]

120. Kumar, A.; Singh, P.; Kulkarni, N.; Kaur, D. Structural and optical studies of nanocrystalline $\mathrm{V}_{2} \mathrm{O}_{5}$ thin films. Thin Solid Film 2008, 516, 912-918. [CrossRef]

121. Gan, Y.X.; Gan, J.B. Measuring the electrical and photonic properties of cobalt oxide-containing composite carbon fibers. J. Compos. Sci. 2020, 4, 156. [CrossRef] 